\title{
Novel Supramolecular Side-Chain Banana-Shaped Liquid Crystalline Polymers Containing Covalent- and Hydrogen-Bonded Bent Cores
}

\author{
Ling-Yung Wang, Hsin-Yi Tsai, and Hong-Cheu Lin* \\ Department of Materials Science and Engineering, National Chiao Tung University, Hsinchu, Taiwan, ROC
}

Received September 2, 2009; Revised Manuscript Received December 15, 2009

\begin{abstract}
Novel supramolecular side-chain banana-shaped liquid crystalline (LC) polymer complexes $\mathbf{A} \boldsymbol{m} \mathbf{B} n-\mathbf{N}$ bearing various $(\boldsymbol{m} / \boldsymbol{n})$ molar ratios of hydrogen- and covalent-bonded bent-core components were acquired by the free radical polymerization, where the hydrogen-bonded (H-bonded) structures were executed via mixing equimolar portions of proton donor (H-donor) polymers $\mathbf{A} \boldsymbol{m} \mathbf{B} \boldsymbol{n}$ (homopolymers/ copolymers) and pyridyl proton acceptor (H-acceptor) bent cores (small molecules). The influences of the molar ratios of bent-core H-bonded components in side-chain banana-shaped LC polymers and their corresponding polymer complexes on mesomorphic and electro-optical properties were first investigated. The voltage-dependent antiferroelectric properties of spontaneous polarization (Ps) values in the polar smectic phase of the supramolecular side-chain banana-shaped copolymers were also reported. The nematic and tilted smectic phases were verified by XRD measurements, and the SmCP phase was further confirmed by the triangular wave method. Surprisingly, a novel enantiotropic polar smectic $\left(\mathrm{SmCP}_{\mathrm{A}}\right)$ phase was generated in some bent-core side-chain polymer complexes AmBn-N. Therefore, a special approach to constructing (or stabilizing) the SmCP phase was first developed in this study by copolymerization of bent-core covalent- and $\mathrm{H}$-bonded units in side-chain polymer complexes (with proper $\boldsymbol{m} / \boldsymbol{n}$ molar ratios of 16/1 and 10/1) from both bent-core covalent- and H-bonded monomers (i.e., B and A-N units, respectively) without the SmCP phase.
\end{abstract}

\section{Introduction}

Liquid crystalline (LC) materials bearing bent-shaped mesogens become interesting topics due to their special electro-optical properties, such as spontaneous polarized capabilities and nonlinear optics. ${ }^{1-5}$ Since the first example of bent-core molecules, which possessed achiral configurations but with chiral characteristics, was published and revealed antiferroelectric effects, bentshaped LC derivatives with banana-shaped (or bent-core) mesogens were developed and conferred fascinating optical and electrical properties. ${ }^{6}$ Consequently, their particular mesophases, including columnar stacking, tilted smectic phases, and threedimensional structures, named $\mathrm{B} 1$ to $\mathrm{B} 7$ phases were explored and identified. The most prevailingly investigated $\mathrm{B} 2$ phase revealed ferroelectric $(\mathrm{F}) /$ antiferroelectric $(\mathrm{A})$ properties, which possessed identical/inverse polarizations, and synclinic (S)/anticlinic (A) arrangements with alike/opposite molecular tilted aspects between layer to layer, respectively. ${ }^{6,7}$ Hence, depending on the polar directions and molecular tilted directions in neighboring layers, four kinds of different molecular architectures were categorized to homochiral $\left(\mathrm{SmC}_{\mathrm{A}} \mathrm{P}_{\mathrm{A}}\right.$ and $\left.\mathrm{SmC}_{\mathrm{S}} \mathrm{P}_{\mathrm{F}}\right)$ and racemic $\left(\mathrm{SmC}_{\mathrm{S}} \mathrm{P}_{\mathrm{A}}\right.$ and $\left.\mathrm{SmC}_{\mathrm{A}} \mathrm{P}_{\mathrm{F}}\right)$ conditions, respectively.

In general, banana-shaped LC configurations are appropriate lengths of flexible terminal chains attached to mesogenic bent cores containing a central core with a suitable bent angle linked through polar functional groups. The structural variations of achiral molecular designs, such as the central parts, lateral substituents, linking groups, terminal chains, and the number of rings, would affect their physical properties to different extents in small molecular systems. Recently, polymolecular systems, i.e., dimeric, ${ }^{8-13}$ polymeric, ${ }^{14-18}$ and dendritic ${ }^{192}$ frameworks, were

*Author for correspondence: Tel 8863-5712121 ext 55305; Fax 88635724727; e-mail linhc@cc.nctu.edu.tw. also developed to investigate the influence of molecular configurations on mesomorphic and electro-optical properties. However, the most interesting issue of bent-core molecules is to retain the lamellar organization with spontaneous polarization and electric-optical switching properties which need to be further realized due to their possible applications in fast responsive $\mathrm{LCD}$ devices. Moreover, some novel supramolecular bent-core interactions or their nanocomposite architectures have been integrated into organic or inorganic parts to display special electrooptical characteristics, for instance, bent-core derivatives embedded with nanoparticles, ${ }^{21}$ H-bonded bent-core supramolecules, ${ }^{22-28}$ and bent-core structures with silyl and siloxyl linkages. ${ }^{29-31}$

Concerning the fully covalent-bonded bent-core polymers, since the example of the bent-core main-chain polymer with a polar smectic mesophase was synthesized, ${ }^{15}$ the polar switching behavior has been declared to exist in the polymeric framework. Up to now, even if the first case of the bent-core side-chain polymer, where the bent-core units were connected by siloxyl spacers, displayed clear ferroelectric switching properties, ${ }^{14}$ just only scarce cases of bent-core side-chain polymers were achieved with barely detectable polar switching properties. ${ }^{17}$ With regard to H-bonded bent-core structures, different molecular designs in terms of small molecules ${ }^{24,25,27,28}$ and polymers (side-chain polymers) ${ }^{26}$ have been developed and reported, but very few $\mathrm{H}$ bonded bent-core structures with ferroelectric or antiferroelectric properties have been measured and analyzed. ${ }^{25,27}$ Therefore, more detailed researches of $\mathrm{H}$-bonded bent-core molecules (as well as polymers) with special ferroelectric or antiferroelectric properties may be beneficial for the electro-optical applications of supramolecular materials.

In our previous studies, the singly $\mathrm{H}$-bonded five-ring bananashaped supramolecule (complex H12) ${ }^{32 a}$ showed lower mesophasic transition temperatures and enthalpies than those of the 


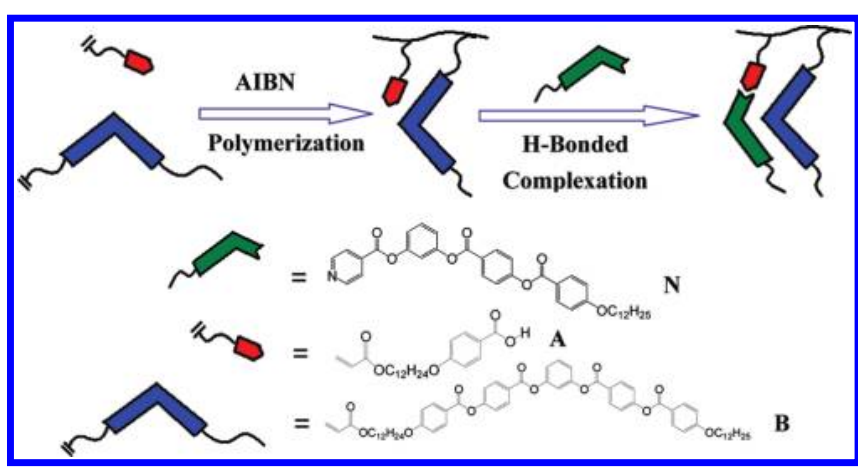

Figure 1. Chemical structures and formation procedures of bent-core side-chain polymer complexes $(\mathbf{A} \boldsymbol{m} \mathbf{B} \boldsymbol{n}-\mathbf{N})$ with covalent- and H-bonded components (B and A-N units, respectively).

fully covalent-bonded five-ring banana-shaped analogue (compound S12) ${ }^{32 \mathrm{~b}}$ as shown in Figure S1 of the Supporting Information, which suggested that the H-bonded framework exhibited a softer mesogenic arrangement than the covalentbonded architecture. On the other hand, the H-bonded rodlike (or banana-shaped) molecules may be stabilized by the fully covalent-bonded counterparts (or as dopants) to have more steady electro-optical properties. Considering both merits of covalentand $\mathrm{H}$-bonded molecular designs, there might be some intermediate or even premium properties can be achieved by blending or copolymerizing two types of covalent- and H-bonded analogues. ${ }^{33,26 \mathrm{~b}}$ Therefore, H-bonded bent-core units would behave as softer skeletons to tune the suitable molecular arrangements in harmony with the fully bent-core covalent-bonded units in polymeric side-chain structures. Hence, our molecular designs of incorporating bent-core covalent-bonded and $\mathrm{H}$-bonded moieties in various molar ratios were proceeded in this study of bent-core side-chain polymers (see Figure 1) to modulate the molecular organization and optimize the polar switching behavior.

\section{Experimental Section}

Characterization Methods. ${ }^{1} \mathrm{H}$ NMR spectra were recorded on a Varian Unity $300 \mathrm{MHz}$ spectrometer using $d_{6}$-dioxane and $\mathrm{CDCl}_{3}$ as solvents, and mass measurements were determined on a Micromass TRIO-2000 GC-MS. Elemental analyses (EA) were performed on a Heraeus CHN-OS RAPID elemental analyzer. Gel permeation chromatography (GPC) analyses were conducted on a Waters 1515 separation module using polystyrene as a standard and THF as an eluant. Mesophasic textures were characterized by polarizing optical microscopy (POM) using a Leica DMLP equipped with a hot stage. Infrared (IR) spectra were investigated by a Perkin-Elmer Spectrum 100 instrument. Temperatures and enthalpies of phase transitions were determined by differential scanning calorimetry (DSC, model: Perkin-Elmer Pyris 7) under $\mathrm{N}_{2}$ at a heating and cooling rate of $10{ }^{\circ} \mathrm{C} \mathrm{min}^{-1}$. Synchrotron powder X-ray diffraction (XRD) measurements were performed at beamline BL17A of the National Synchrotron Radiation Research Center (NSRRC), Taiwan, where the wavelength of X-ray was $1.33366 \AA$. The powder samples were packed into capillary tubes and heated by a heat gun, whose temperature controller was programmable by a PC with a PID feedback system. The scattering angle theta was calibrated by a mixture of silver behenate and silicon. The electro-optical properties were determined in commercially available ITO cells (from Mesostate Corp., thickness $=4.25 \mu \mathrm{m}$, active area $=1 \mathrm{~cm}^{2}$ ) with rubbed polyimide alignment coatings (parallel rubbing direction). A digital oscilloscope (Tektronix TDS-3012B) was used in these measurements.

Synthesis. Synthesis of Monomers. All synthetic procedures of monomers A (H-donor monomer) and B (bent-core covalent-bonded monomer) as well as $\mathrm{H}$-acceptor $\mathbf{N}$ are demonstrated in Scheme 1. The synthetic details of all compounds in Scheme 1 are shown in the following descriptions.

12-Bromododecanol (1). Doecan-1,12-diol (20.2 g, $100 \mathrm{mmol})$ and $\mathrm{HBr}(8.1 \mathrm{~g}, 100 \mathrm{mmol})$ were dissolved in toluene solvent to react at $60^{\circ} \mathrm{C}$ for $24 \mathrm{~h}$, and side product $\mathrm{H}_{2} \mathrm{O}$ could be removed by Dean Stark installation. After then, the reacted solution was extracted by ethyl acetate (EA) and water, and the organic liquid layer was purified by column chromatography to give a liquid product (14.9 g, $56 \mathrm{mmol})$. Yield: $56 \%$. ${ }^{1} \mathrm{H}$ NMR $(300 \mathrm{MHz}$, $\left.\mathrm{CDCl}_{3}\right) \delta(\mathrm{ppm}): 3.57\left(\mathrm{t}, J=6.6 \mathrm{~Hz}, 2 \mathrm{H},-\mathrm{OCH}_{2}-\right), 3.39(\mathrm{t}, J=$ $\left.6.9 \mathrm{~Hz}, 2 \mathrm{H}, \mathrm{Br}-\mathrm{CH}_{2}-\right), 3.19(\mathrm{~s}, 1 \mathrm{H},-\mathrm{OH}), 2.04-1.80(\mathrm{~m}, 2 \mathrm{H}$, $\left.\mathrm{Br}-\mathrm{CH}_{2} \mathrm{CH}_{2}-\right), \quad 1.56-1.49\left(\mathrm{~m}, 2 \mathrm{H}, \mathrm{HO}-\mathrm{CH}_{2} \mathrm{CH}_{2}-\right)$, $1.44-1.21\left(\mathrm{~m}, 16 \mathrm{H},-\mathrm{CH}_{2}-\right)$.

Compound (Cpd) 2. 12-Bromododecanol (1) (14.9 g, 56 mmol), methyl 4-hydroxybenzoate $(7.76 \mathrm{~g}, 51 \mathrm{mmol})$, and potassium carbonate $\left(\mathrm{K}_{2} \mathrm{CO}_{3}\right)(10.6 \mathrm{~g}, 76.5 \mathrm{mmol})$ were dissolved in acetone solvent to react at reflux temperature for $20 \mathrm{~h}$. After that, water was added to dissolve the inorganic salt, and a white precipitation was produced. Subsequently, the white powder was washed by hexane to get a pure product (15.6 g, $46.4 \mathrm{mmol})$. Yield: $91 \%$. ${ }^{1} \mathrm{H}$ NMR $\left(300 \mathrm{MHz}, \mathrm{CDCl}_{3}\right) \delta(\mathrm{ppm})$ : $7.95(\mathrm{~d}, J=9.0 \mathrm{~Hz}, 2 \mathrm{H}, \mathrm{Ar}-\mathrm{H}), 6.87(\mathrm{~d}, J=9.0 \mathrm{~Hz}, 2 \mathrm{H}, \mathrm{Ar}-\mathrm{H})$, $3.97\left(\mathrm{t}, J=6.3 \mathrm{~Hz}, 2 \mathrm{H},-\mathrm{OCH}_{2}-\right), 3.85\left(\mathrm{~s}, 3 \mathrm{H},-\mathrm{OCH}_{3}\right), 3.61$ $\left(\mathrm{m}, 2 \mathrm{H},-\mathrm{CH}_{2} \mathrm{OH}\right), 1.79(\mathrm{~s}, 1 \mathrm{H},-\mathrm{OH}), 1.26\left(\mathrm{~m}, 20 \mathrm{H},-\mathrm{CH}_{2}-\right)$.

Compound $(C p d) 3$. Cpd $2(15.6 \mathrm{~g}, 46.4 \mathrm{mmol})$ and potassium hydroxide $(\mathrm{KOH})(10.4 \mathrm{~g}, 185.6 \mathrm{mmol})$ were dissolved in ethanol solvent to reflux and react for $16 \mathrm{~h}$. After cooling reacted liquid to room temperature, $\mathrm{HCl}(10 \mathrm{vol} \%$ in water) solution was added to react $30 \mathrm{~min}$. The precipitation was filtered, and a white powder was formed. The powder was recrystallized by ethanol and hexane (1:3 vol) to collect a pure white product (14.2 g, $44.1 \mathrm{mmol})$. Yield: 95\% . ${ }^{1} \mathrm{H}$ NMR (300 MHz, $\left.\mathrm{CDCl}_{3}\right) \delta$ (ppm): 7.92 (d, $J=8.7 \mathrm{~Hz}, 2 \mathrm{H}, \mathrm{Ar}-\mathrm{H}), 6.92(\mathrm{~d}, J=8.7 \mathrm{~Hz}, 2 \mathrm{H}$, $\mathrm{Ar}-\mathrm{H}), 4.00\left(\mathrm{t}, J=6.6 \mathrm{~Hz}, 2 \mathrm{H},-\mathrm{OCH}_{2}-\right), 3.45(\mathrm{t}, J=6.3 \mathrm{~Hz}$, $\left.2 \mathrm{H},-\mathrm{CH}_{2} \mathrm{OH}\right), 2.06(\mathrm{~s}, 1 \mathrm{H},-\mathrm{OH}), 1.78(\mathrm{~m}, 2 \mathrm{H}$, $\left.-\mathrm{CH}_{2} \mathrm{CH}_{2} \mathrm{OH}\right), 1.29\left(\mathrm{~m}, 18 \mathrm{H},-\mathrm{CH}_{2}-\right)$.

$H$-Donor Monomer $(\boldsymbol{A})$. The addition of terminal acryl group on cpd $\mathbf{2}$ was proceeded by the reaction of acryloyloxy chloride $(6.0 \mathrm{~g}, 66.2 \mathrm{mmol})$ and cpd $2(14.2 \mathrm{~g}, 44.1 \mathrm{mmol})$ in 1,4-dioxane solvent with an organic base of dimethylaniline (DMA) (5.88 g, $48.5 \mathrm{mmol}$ ) under nitrogen to react at room temperature for $24 \mathrm{~h}$. When the reaction was finished, a dilute $\mathrm{HCl}$ solution (10 vol $\%$ in water) was added to the reacted solution to form a white powder. The product was purified by column chromatography to give a white product $(9.13 \mathrm{~g}, 24.3 \mathrm{mmol})$. Yield: $55 \% .{ }^{1} \mathrm{H}$ NMR $\left(300 \mathrm{MHz}, \mathrm{CDCl}_{3}\right) \delta(\mathrm{ppm}): 8.03(\mathrm{~d}, J=9.0 \mathrm{~Hz}$, $2 \mathrm{H}, \mathrm{Ar}-\mathrm{H}), 6.91(\mathrm{~d}, J=9.0 \mathrm{~Hz}, 2 \mathrm{H}, \mathrm{Ar}-\mathrm{H}), 6.41(\mathrm{~d}, J=18 \mathrm{~Hz}$, $\left.1 \mathrm{H},-\mathrm{CH}=\mathrm{CH}_{2}\right), 6.35(\mathrm{~m}, 1 \mathrm{H},=C H-), 6.07(\mathrm{~d}, J=9.0 \mathrm{~Hz}, 1 \mathrm{H}$, $\left.-\mathrm{CH}=\mathrm{CH}_{2}\right), 4.13\left(\mathrm{t}, J=6.6 \mathrm{~Hz}, 2 \mathrm{H}, \mathrm{Ar}-\mathrm{OCH}_{2}-\right), 4.00(\mathrm{t}, J=6.3$ $\left.\mathrm{Hz}, 2 \mathrm{H}, \mathrm{C}=\mathrm{C}-\mathrm{OCH}_{2}-\right), 1.79\left(\mathrm{~m}, 2 \mathrm{H}, \mathrm{Ar}-\mathrm{OCHH}_{2} \mathrm{CH}_{2}-\right), 1.63$ (m, $\left.2 \mathrm{H}, \mathrm{C}=\mathrm{C}-\mathrm{OCHH}_{2} \mathrm{CH}_{2}-\right), 1.26\left(\mathrm{~m}, 16 \mathrm{H},-\mathrm{CH}_{2}-\right.$ ). $\mathrm{MS}(\mathrm{EI})$ : $m / z\left[\mathrm{M}^{+}\right]$377; calcd $m / z\left[\mathrm{M}^{+}\right]$376.5. EA: Calcd for $\mathrm{C}_{22} \mathrm{H}_{32} \mathrm{O}_{5}$ : C, 70.18; H, 8,57. Found: C, 70.33; H, 8.52.

Compound (Cpd) 4. Cpd 3(4.27 g, $10 \mathrm{mmol})$, resorcinol (1.1 g, $10 \mathrm{mmol}), N, N$-dicyclohexylcarbodiimide (DCC) $(2.27 \mathrm{~g}, 11$ mmol), and a catalytic amount of 4 -( $N, N$-dimethylamino)pyridine (DMAP) $(50 \mathrm{mg})$ were dissolved in dry dichloromethane (DCM) under nitrogen to react at room temperature for $15 \mathrm{~h}$, where the starting reactant 3 was a well-known structure and was synthesized by following the literature procedure. ${ }^{34}$ The precipitated dicyclohexylurea (DCU) was filtered off and washed with an excess of DCM $(20 \mathrm{~mL})$. The filtrate was extracted with water and DCM, and the organic liquid layer was dried over anhydrous magnesium sulfate. After removal of the solvent by evaporation under reduced pressure, the residue was recrystallized from ethanol to give a white solid (2.28 g, 4.4 mmol). Yield: $44 \% .{ }^{1} \mathrm{H}$ NMR $\left(300 \mathrm{MHz}, \mathrm{CDCl}_{3}\right) \delta$ (ppm): 8.25 $(\mathrm{d}, J=8.7 \mathrm{~Hz}, 2 \mathrm{H}, \mathrm{Ar}-\mathrm{H}), 8.14(\mathrm{~d}, J=9.0 \mathrm{~Hz}, 2 \mathrm{H}, \mathrm{Ar}-\mathrm{H}), 7.40$ $(\mathrm{d}, J=8.7 \mathrm{~Hz}, 2 \mathrm{H}, \mathrm{Ar}-\mathrm{H}), 7.22(\mathrm{t}, J=8.1 \mathrm{~Hz}, 1 \mathrm{H}, \mathrm{Ar}-\mathrm{H}), 7.03$ 
Scheme 1. Synthetic Routes of Monomers A and B along with Pyridyl H-Acceptor $\mathbf{N}^{a}$

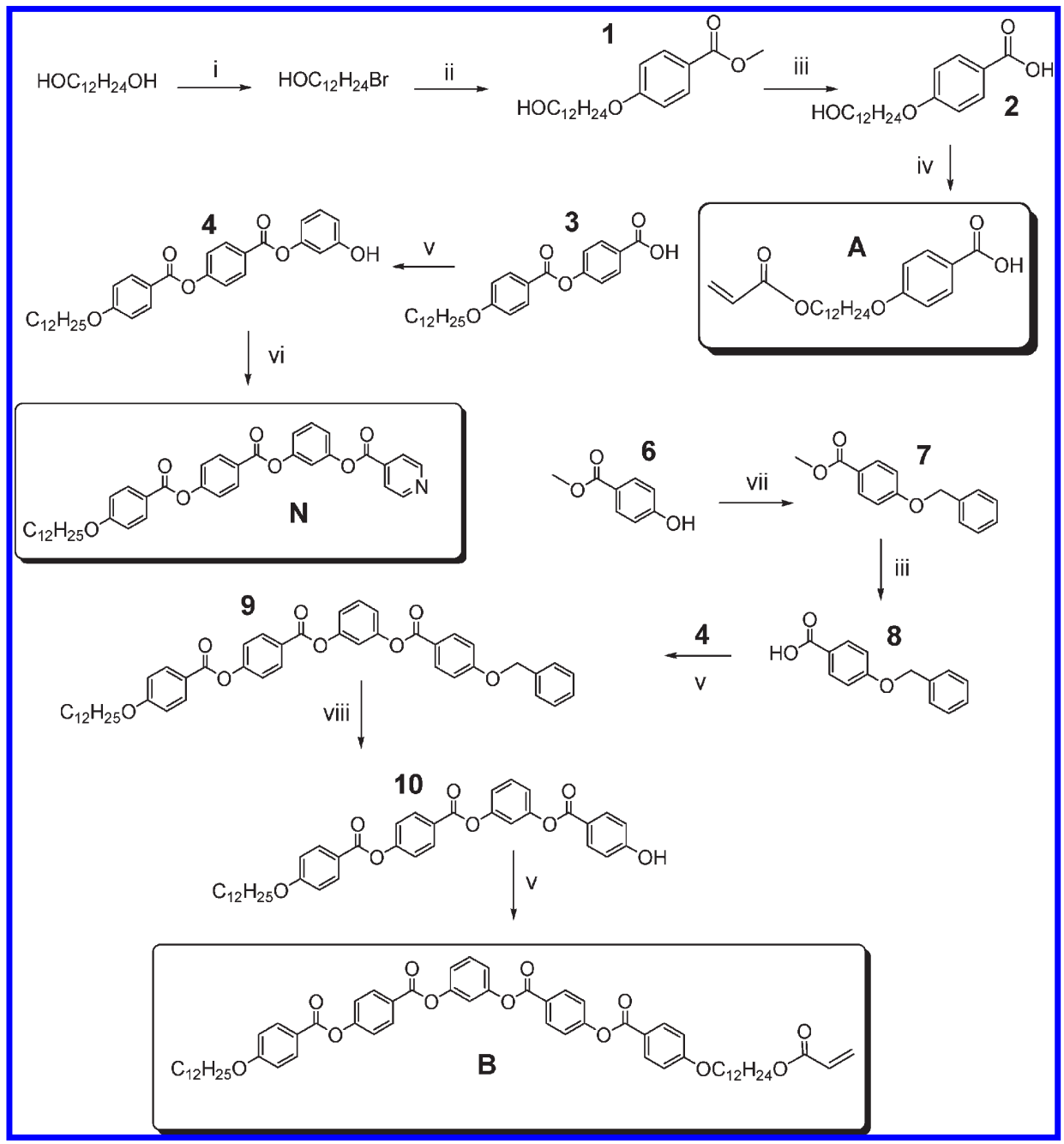

${ }^{a}$ Conditions and reagents: (i) $\mathrm{HBr}$, toluene, (ii): methyl 4-hydroxybenzoate, $\mathrm{K}_{2} \mathrm{CO}_{3}$, acetone; (iii) $\mathrm{KOH}$, ethanol; (iv) acryloyloxy chloride, DMA, 1,4-dioxane; (v) DCC, DMAP, DCM; (vi) isonicotinoyl chloride hydrochloride, triethylamine, DCM; (vii) benzyl bromide, $\mathrm{K}_{2} \mathrm{CO}_{3}$, acetone; (viii) Pd/C, $\mathrm{H}_{2}$, THF.

$(\mathrm{d}, J=9.0 \mathrm{~Hz}, 2 \mathrm{H}, \mathrm{Ar}-\mathrm{H}), 6.71-6.66(\mathrm{~m}, 3 \mathrm{H}, \mathrm{Ar}-\mathrm{H}), 4.06(\mathrm{t}$, $\left.J=6.6 \mathrm{~Hz}, 2 \mathrm{H}, \mathrm{OCH}_{2}\right), 1.80\left(\mathrm{~m}, 2 \mathrm{H}, \mathrm{OCH}_{2} \mathrm{CH}_{2}\right), 1.47-1.28(\mathrm{~m}$, $\left.18 \mathrm{H}, \mathrm{CH}_{2}\right), 0.88\left(\mathrm{t}, \mathrm{J}=6.3 \mathrm{~Hz}, 3 \mathrm{H}, \mathrm{CH}_{3}\right)$.

Pyridyl H-Acceptor $(N)$. A mixture of cpd 4 (2.28 g, 4.4 $\mathrm{mmol})$, isonicotinoyl chloride hydrochloride $(0.86 \mathrm{~g}, 4.84$ $\mathrm{mmol})$, and triethylamine $(0.53 \mathrm{~g}, 5.3 \mathrm{mmol})$ were dissolved in dry DCM under nitrogen to react at room temperature for $8 \mathrm{~h}$. After workup, the solvent was extracted with water and DCM, and organic liquid layer was dried over anhydrous magnesium sulfate. After removal of the solvent by evaporation under reduced pressure, the residue was purified by column chromatography and recrystallized by DCM and hexane (1:4 vol) to give a white solid (2.62 g, $4.2 \mathrm{mmol})$. Yield: $95 \%$. ${ }^{1} \mathrm{H}$ NMR $(300 \mathrm{MHz}$, $\left.\mathrm{CDCl}_{3}\right): \delta 8.89(\mathrm{~d}, J=4.2 \mathrm{~Hz}, 2 \mathrm{H}, \mathrm{Ar}-\mathrm{H}), 8.22(\mathrm{~d}, J=8.7 \mathrm{~Hz}$, $2 \mathrm{H}, \mathrm{Ar}-\mathrm{H}), 8.08(\mathrm{~d}, J=8.7 \mathrm{~Hz}, 2 \mathrm{H}, \mathrm{Ar}-\mathrm{H}), 8.01(\mathrm{~d}, J=4.2$ $\mathrm{Hz}, 2 \mathrm{H}, \mathrm{Ar}-\mathrm{H}), 7.59(\mathrm{t}, J=8.1 \mathrm{~Hz}, 1 \mathrm{H}, \mathrm{Ar}-\mathrm{H}), 7.51(\mathrm{~d}, J=9.0$ $\mathrm{Hz}, 2 \mathrm{H}, \mathrm{Ar}-\mathrm{H}), 7.41$ (s, 1H, Ar-H), 7.32 (br, 2H, Ar-H), 7.10 $(\mathrm{d}, J=9.0 \mathrm{~Hz}, 2 \mathrm{H}, \mathrm{Ar}-\mathrm{H}) ; 4.07\left(\mathrm{t}, J=6.3 \mathrm{~Hz}, 2 \mathrm{H}, \mathrm{OCH}_{2}\right), 1.74$ (br, $\left.2 \mathrm{H}, \mathrm{OCH}_{2} \mathrm{CH}_{2}\right), 1.23\left(\mathrm{br}, 18 \mathrm{H}, \mathrm{CH}_{2}\right), 0.84(\mathrm{t}, J=6.3 \mathrm{~Hz}, 3 \mathrm{H}$, $\mathrm{CH}_{3}$ ). MS (EI): $\mathrm{m} / z\left[\mathrm{M}^{+}\right]$624; calcd $m / z\left[\mathrm{M}^{+}\right]$623.7. EA: Calcd for $\mathrm{C}_{38} \mathrm{H}_{41} \mathrm{NO}_{7}: \mathrm{N}, 2.25 \mathrm{C}, 73.17 ; \mathrm{H}, 6.63$. Found: N, $2.44 \mathrm{C}$, $73.25 ; \mathrm{H}, 6.75$.

Compound (Cpd) 7. Methyl 4-hydroxybenzoate (cpd 6) (3.0 g, $20 \mathrm{mmol})$, benzyl bromide $(3.76 \mathrm{~g}, 22 \mathrm{mmol})$, and $\mathrm{K}_{2} \mathrm{CO}_{3}(4.15 \mathrm{~g}$, $30 \mathrm{mmol}$ ) were dissolved in acetone solvent and reacted at reflux temperature for $10 \mathrm{~h}$. After removing acetone at reduced pressure, water was added and a precipitate was produced immediately. The crude product was recrystallized by acetone and hexane (1:4 vol) to give a white solid (4.7 g, $19.4 \mathrm{mmol})$. Yield: $97 \%$. ${ }^{1} \mathrm{H}$ NMR $\left(300 \mathrm{MHz}, \mathrm{CDCl}_{3}\right): \delta 7.03(\mathrm{~d}, J=9.0 \mathrm{~Hz}$, $2 \mathrm{H}, \mathrm{Ar}-\mathrm{H}), 6.63-6.50(\mathrm{~m}, 5 \mathrm{H}, \mathrm{Ar}-\mathrm{H}), 6.35(\mathrm{~d}, J=9.0 \mathrm{~Hz}$, $\mathrm{Ar}-\mathrm{H}), 4.38$ (s, $\left.2 \mathrm{H}, \mathrm{OCH}_{2}\right), 2.49\left(\mathrm{~s}, 3 \mathrm{H}, \mathrm{OCH}_{3}\right)$.

Compound $(C p d)$ 8. Cpd 7 (4.7 g, $19.4 \mathrm{mmol})$ and $\mathrm{KOH}(4.35$ $\mathrm{g}, 77.6 \mathrm{mmol})$ were dissolved in ethanol and reacted at reflux temperature for $10 \mathrm{~h}$. $\mathrm{HCl}$ solution ( $10 \mathrm{vol} \%$ in water) was added to produce a precipitate, and the crude product was recrystallized by THF and hexane $(1: 10 \mathrm{vol})$ to give a white solid (4.34 g, $19.0 \mathrm{mmol})$. Yield: $98 \%$. ${ }^{1} \mathrm{H}$ NMR (300 MHz, DMSO) $\delta 7.87(\mathrm{~d}, J=9.0 \mathrm{~Hz}, 2 \mathrm{H}, \mathrm{Ar}-\mathrm{H})$, 7.46-7.33 (m, 5H, Ar-H), 7.07 (d, $J=9.0 \mathrm{~Hz}, 2 \mathrm{H}, \mathrm{Ar}-\mathrm{H})$, $5.17\left(\mathrm{~s}, 2 \mathrm{H}, \mathrm{OCH}_{2}\right)$.

Compound $(C p d)$ 9. Cpd 8 (4.34 g, $19.0 \mathrm{mmol})$ and cpd 4 $(9.85 \mathrm{~g}, 19.0 \mathrm{mmol})$ were dissolved in dry DCM solvent and reacted with a catalytic amount of DMAP $(0.46 \mathrm{~g}, 3.8 \mathrm{mmol})$ and DCC $(4.31 \mathrm{~g}, 20.9 \mathrm{mmol})$ under nitrogen for $24 \mathrm{~h}$. The organic solution was extracted by DCM and water $(1: 1 \mathrm{vol})$ and recrystallized by DCM and ethanol $(1: 10 \mathrm{vol})$ to yield a white solid $(7.89 \mathrm{~g}, 10.8$ mmol). Yield: $57 \%$. ${ }^{1} \mathrm{H}$ NMR (300 MHz, $d$-dioxane) $\delta$ (ppm): 8.26 $(\mathrm{d}, J=9.0 \mathrm{~Hz}, 2 \mathrm{H}, \mathrm{Ar}-\mathrm{H}), 8.13(\mathrm{~d}, J=9.0 \mathrm{~Hz}, 2 \mathrm{H}, \mathrm{Ar}-\mathrm{H})$, 7.44-7.29 (m, 10H, Ar-H), 6.97 (d, $J=9.0 \mathrm{~Hz}, 2 \mathrm{H}, \mathrm{Ar}-\mathrm{H})$, 6.91-6.81 (m, 7H, $\mathrm{Ar}-\mathrm{H}), 5.06\left(\mathrm{~s}, 1 \mathrm{H},-\mathrm{Ar}-\mathrm{O}-\mathrm{CH}_{2}-\mathrm{Ar}\right)$, $4.04\left(\mathrm{t}, J=6.6 \mathrm{~Hz}, 2 \mathrm{H}, \mathrm{OCH}_{2}\right), 1.81(\mathrm{t}, J=6.3 \mathrm{~Hz}, 2 \mathrm{H}$, 
$\left.\mathrm{OCH}_{2} \mathrm{CH}_{2}\right), 1.46-1.25\left(\mathrm{~m}, 18 \mathrm{H},-\mathrm{CH}_{2}-\right), 0.86(\mathrm{t}, J=6.3 \mathrm{~Hz}, 3 \mathrm{H}$, $\mathrm{CH}_{3}$ ).

Compound (Cpd) 10. Cpd 9 (7.89 g, $10.8 \mathrm{mmol})$ and $\mathrm{Pd} / \mathrm{C}$ catalyst $(0.5 \mathrm{~g})$ were mixed in THF solvent under hydrogen to react at room temperature for $20 \mathrm{~h}$. The catalyst was removed by filtration through Celite and washed with THF. The solvent was removed by evaporation under reduced pressure, and the crude product was recrystallized by THF and hexane $(1: 10 \mathrm{vol})$ to produce a white solid $(5.52 \mathrm{~g}, 8.64 \mathrm{mmol})$. Yield: $80 \%$. ${ }^{1} \mathrm{H}$ NMR (300 MHz, $d$-dioxane): $\delta(\mathrm{ppm}): 8.28(\mathrm{~d}, J=9.0 \mathrm{~Hz}, 2 \mathrm{H}, \mathrm{Ar}-\mathrm{H})$, $8.13(\mathrm{~d}, J=9.0 \mathrm{~Hz}, 2 \mathrm{H}, \mathrm{Ar}-\mathrm{H}), 8.05(\mathrm{~d}, J=8.7 \mathrm{~Hz}, 2 \mathrm{H}, \mathrm{Ar}-\mathrm{H})$, $7.47(\mathrm{t}, J=8.1 \mathrm{~Hz}, 1 \mathrm{H}, \mathrm{Ar}-\mathrm{H}), 7.41(\mathrm{~d}, J=8.7 \mathrm{~Hz}, 2 \mathrm{H}, \mathrm{Ar}-\mathrm{H})$, $7.22(\mathrm{~s}, 1 \mathrm{H}, \mathrm{Ar}-\mathrm{H}), 7.19-7.14(\mathrm{~m}, 4 \mathrm{H}, \mathrm{Ar}-\mathrm{H}), 7.03(\mathrm{~d}, J=9.0$ $\mathrm{Hz}, 2 \mathrm{H}, \mathrm{Ar}-\mathrm{H}), 6.86(\mathrm{~d}, J=8.7 \mathrm{~Hz}, 2 \mathrm{H}, \mathrm{Ar}-\mathrm{H}), 4.05(\mathrm{t}, J=6.3$ $\left.\mathrm{Hz}, 2 \mathrm{H},-\mathrm{OCH}_{2}-\right), 1.80\left(\mathrm{~m}, 2 \mathrm{H},-\mathrm{OCHH}_{2} \mathrm{CH}_{2}-\right), 1.28(\mathrm{~m}$, $\left.18 \mathrm{H},-\mathrm{CH}_{2}-\right), 0.88\left(\mathrm{t}, J=6.3 \mathrm{~Hz}, 3 \mathrm{H},-\mathrm{CH}_{3}\right)$.

Bent-Core Covalent-Bonded Monomer (B). Cpd A (3.58 g, 9.50 mmol), cpd 10 (5.52 g, $8.64 \mathrm{mmol})$, DCC (1.96 g, $9.5 \mathrm{mmol})$, and DMAP $(0.21 \mathrm{~g}, 1.73 \mathrm{mmol})$ were dissolved in THF solvent under nitrogen to react at room temperature for $24 \mathrm{~h}$. The solution was extracted by DCM and water and purified by column chromatography to acquire a white solid $(5.17 \mathrm{~g}, 5.18 \mathrm{mmol})$. Yield: $60 \%{ }^{1} \mathrm{H}$ NMR (300 MHz, $d$-dioxane) $\delta(\mathrm{ppm}): 8.25(\mathrm{~d}, J=9.0 \mathrm{~Hz}, 2 \mathrm{H}$, $\mathrm{Ar}-\mathrm{H}), 8.10(\mathrm{~d}, J=8.7 \mathrm{~Hz}, 2 \mathrm{H}, \mathrm{Ar}-\mathrm{H}), 7.48(\mathrm{~d}, J=8.1 \mathrm{~Hz}, 1 \mathrm{H}$, $\mathrm{Ar}-\mathrm{H}), 7.38(\mathrm{~d}, J=9.0 \mathrm{~Hz}, 2 \mathrm{H}, \mathrm{Ar}-\mathrm{H}), 7.25(\mathrm{~s}, 1 \mathrm{H}, \mathrm{Ar}-\mathrm{H}), 7.17$ $(\mathrm{d}, J=8.1 \mathrm{~Hz}, 1 \mathrm{H}, \mathrm{Ar}-\mathrm{H}), 7.01(\mathrm{~d}, J=8.7 \mathrm{~Hz}, 2 \mathrm{H}, \mathrm{Ar}-\mathrm{H}), 6.29(\mathrm{~d}$, $\left.J=17.1 \mathrm{~Hz}, 1 \mathrm{H},-\mathrm{CH}=\mathrm{CH}_{2}\right), 6.08(\mathrm{~m}, 1 \mathrm{H},-\mathrm{CH}=), 5.77(\mathrm{~d}, J=$ $\left.10.2 \mathrm{~Hz}, 1 \mathrm{H},-\mathrm{CH}=\mathrm{CH}_{2}\right), 4.08-4.00\left(\mathrm{~m}, 6 \mathrm{H},-\mathrm{OCH}_{2}-\right)$, $1.78-1.71\left(\mathrm{~m}, 4 \mathrm{H},-\mathrm{OCH}_{2} \mathrm{CH}_{2}-\right), 1.59-1.56(\mathrm{~m}, 2 \mathrm{H}$, $\left.-\mathrm{OCHH}_{2} \mathrm{CH}_{2}-\right), 1.43-1.26\left(\mathrm{~m}, 34 \mathrm{H},-\mathrm{CH}_{2}-\right), 0.84(\mathrm{t}, J=6.3$ $\mathrm{Hz}, 3 \mathrm{H},-\mathrm{CH}_{3}$ ). MS (EI): $m / z\left[\mathrm{M}^{+}\right] 998$; calcd $m / z\left[\mathrm{M}^{+}\right]$997.2. EA: Calcd for $\mathrm{C}_{61} \mathrm{H}_{72} \mathrm{O}_{12}$ : C, 73.47; $\mathrm{H}$, 7.28. Found: C, 73.82; H, 6.95 .

Polymerization. As shown in Scheme 2, the polymerizations of side-chain polymers $\mathbf{A} \boldsymbol{m} \mathbf{B} \boldsymbol{n}$ with various molar ratios were carried out by free radical reactions in dry THF via different input molar ratios (see Table 1) of monomers $\mathbf{A}$ and $\mathbf{B}$ with 2,2'azobis(isobutyronitrile) (AIBN) as an initiator. All reactions were performed under $\mathrm{N}_{2}$ at reflux temperature for $24 \mathrm{~h}$. The produced organic liquids were dropped into fast stirring diethyl ether (EA) solvent to precipitate products and purified again by THF and EA (1:10 vol) to obtain white solids. Yield: $59-73 \%$. For example, cpd A (1.0 g, $2.65 \mathrm{mmol})$ and cpd B (2.65 g, 2.65 mmol) were dissolved in dry THF solvent and reacted with an AIBN initiator ( $44.3 \mathrm{mg}, 0.27 \mathrm{mmol})$ under nitrogen for $24 \mathrm{~h}$. The produced organic liquids were recrystallized by THF and EA (1:10 vol) to yield a white solid $(2.37 \mathrm{~g})$. According to similar manufactured procedures, a series of side-chain polymers $\mathbf{A} \boldsymbol{m} \mathbf{B} \boldsymbol{n}$ $(\boldsymbol{m} / \boldsymbol{n}=1 / 0,16 / 1,10 / 1,4 / 1,1 / 2,1 / 4,1 / 13,0 / 1)$ were prepared by various input molar ratios of monomers $\mathbf{A}$ and $\mathbf{B}$. Furthermore, the extents of polymerization and output molar ratios $(\mathrm{m} / \mathrm{n})$ of polymer products were determined by ${ }^{1} \mathrm{H}$ NMR spectra.

Preparation of Polymer Complexes. All bent-core side-chain polymer complexes $\mathbf{A} \boldsymbol{m} \mathbf{B} \boldsymbol{n}-\mathbf{N}$ were constructed by mixing appropriate molar ratios of $\mathrm{H}$-donor polymers $(\mathbf{A} \boldsymbol{m} \mathbf{B} \boldsymbol{n}$, excluding A0B1) and pyridyl $\mathrm{H}$-acceptor $(\mathbf{N})$ in the solutions of chloroform/THF (ca. 1:1 vol), which were self-assembled into supramolecules by evaporating solvents slowly. For example, homopolymer A1B0 (20 mg) and pyridyl H-acceptor (N) (33.1 $\mathrm{mg}$ ) were dissolved in a mixed solvent of chloroform/THF (ca. $1: 1 \mathrm{vol}$ ) and self-assembled into supramolecules by evaporating solvents slowly. When the solvent were evaporated completely, a white polymer complex of $\mathbf{A 1 B} \mathbf{0}-\mathbf{N}$ was formed. In the same vein, the other polymer complexes A16B1-N, A10B1-N, A4B1N, A1B2-N, A1B5-N, and A1B13-N were also provided.

\section{Results and Discussion}

According to our previous conception, $\mathrm{H}$-donor and bent-core covalent-bonded monomers with acrylate terminal groups were
Scheme 2. Synthetic Approaches of Side-Chain Polymers AmBn (Homopolymers/Copolymers) and Their Corresponding Bent-Core Side-Chain Polymer Complexes AmBn-N

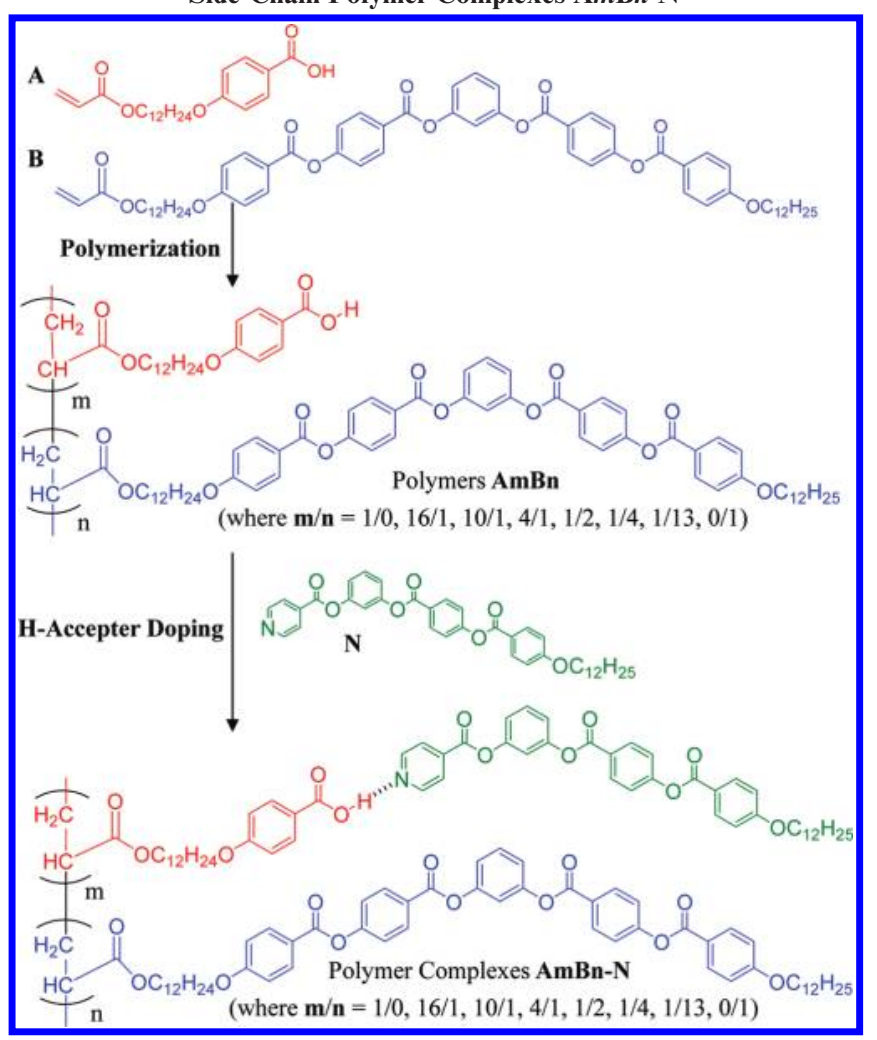

Table 1. Chemical Compositions and Molecular Weights of SideChain Polymers

\begin{tabular}{lcccc}
\hline polymer & $\begin{array}{c}\text { input molar } \\
\text { ratio A:B }\end{array}$ & $\begin{array}{c}\text { output molar } \\
\text { ratio A:B }(m: n)\end{array}$ & $M_{\mathrm{n}}\left(\times 10^{3}\right)$ & PDI \\
\hline A1B0 & $1: 0$ & $1: 0$ & 5.1 & 1.13 \\
A16B1 & $15: 1$ & $16: 1$ & 5.8 & 1.29 \\
A10B1 & $10: 1$ & $10: 1$ & 7.2 & 1.25 \\
A4B1 & $5: 1$ & $4: 1$ & 7.1 & 1.26 \\
A1B2 & $1: 1$ & $1: 2$ & 10.5 & 1.20 \\
A1B5 & $1: 5$ & $1: 5$ & 9.1 & 1.21 \\
A1B13 & $1: 10$ & $1: 13$ & 12.7 & 1.17 \\
A0B1 & $0: 1$ & $0: 1$ & 12.1 & 1.16
\end{tabular}

designed and synthesized. The bent-core covalent-bonded fivering monomer was connected by polar ester groups, and its $\mathrm{H}$-bonded analogue was established as a five-ring supramolecule by blending two complementary components of an acidic proton donor (H-donor with a terminal acrylate) and bent-core proton acceptor (H-acceptor with a terminal pyridine). Then, the H-donor monomer (A) and bent-core covalent-bonded monomer (B) with different molar ratios were copolymerized to obtain H-donor side-chain copolymers/homopolymers $\mathbf{A} \boldsymbol{m} \mathbf{B} \boldsymbol{n}$ (where $\boldsymbol{m}$ and $\boldsymbol{n}$ are repeating units of $\mathbf{A}=\mathrm{H}$-donor structure and $\mathbf{B}=$ covalent-bonded bent-core structure, respectively), and then they were blended with pyridyl $\mathrm{H}$-acceptor $\mathbf{N}$ to form $\mathrm{H}$-bonded bentcore polymer complexes $\mathbf{A} \mathbf{m} \mathbf{B} \boldsymbol{n}-\mathbf{N}$. Therefore, H-donor sidechain copolymers/homopolymers $\mathbf{A} \boldsymbol{m} \mathbf{B} \boldsymbol{n}$ with various molar ratios of $\mathbf{A}$ and $\mathbf{B}$ units were synthesized, where $\boldsymbol{m} / \boldsymbol{n}$ molar ratios are $1 / 0,16 / 1,10 / 1,4 / 1,1 / 2,1 / 5,1 / 13$, and $0 / 1$ as shown in Figure 1 and Table 1 . In addition, the bent-core side-chain LC copolymers bearing both bent-core covalent- and $\mathrm{H}$-bonded components were developed in this study via their corresponding $\mathrm{H}$-bonded polymer complexes $\mathbf{A} \boldsymbol{m} \mathbf{B} \boldsymbol{n}-\mathbf{N}$, which consisted of H-donor sidechain copolymers/homopolymers $(\mathbf{A} \boldsymbol{m} \mathbf{B} \boldsymbol{n})$ and pyridyl H-acceptor $(\mathbf{N})$. The variations of mesomorphic and electro-optical 


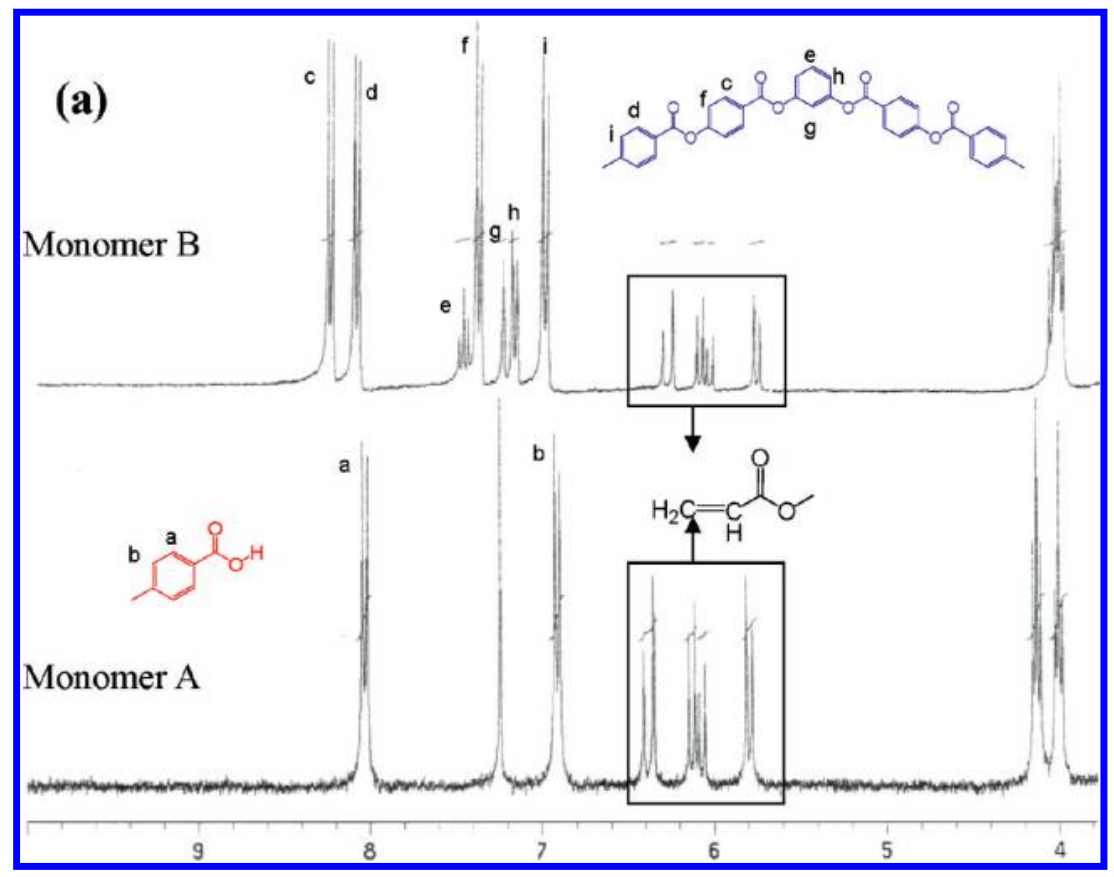

Figure 2. NMR spectra of monomers A and $\mathbf{B}$.

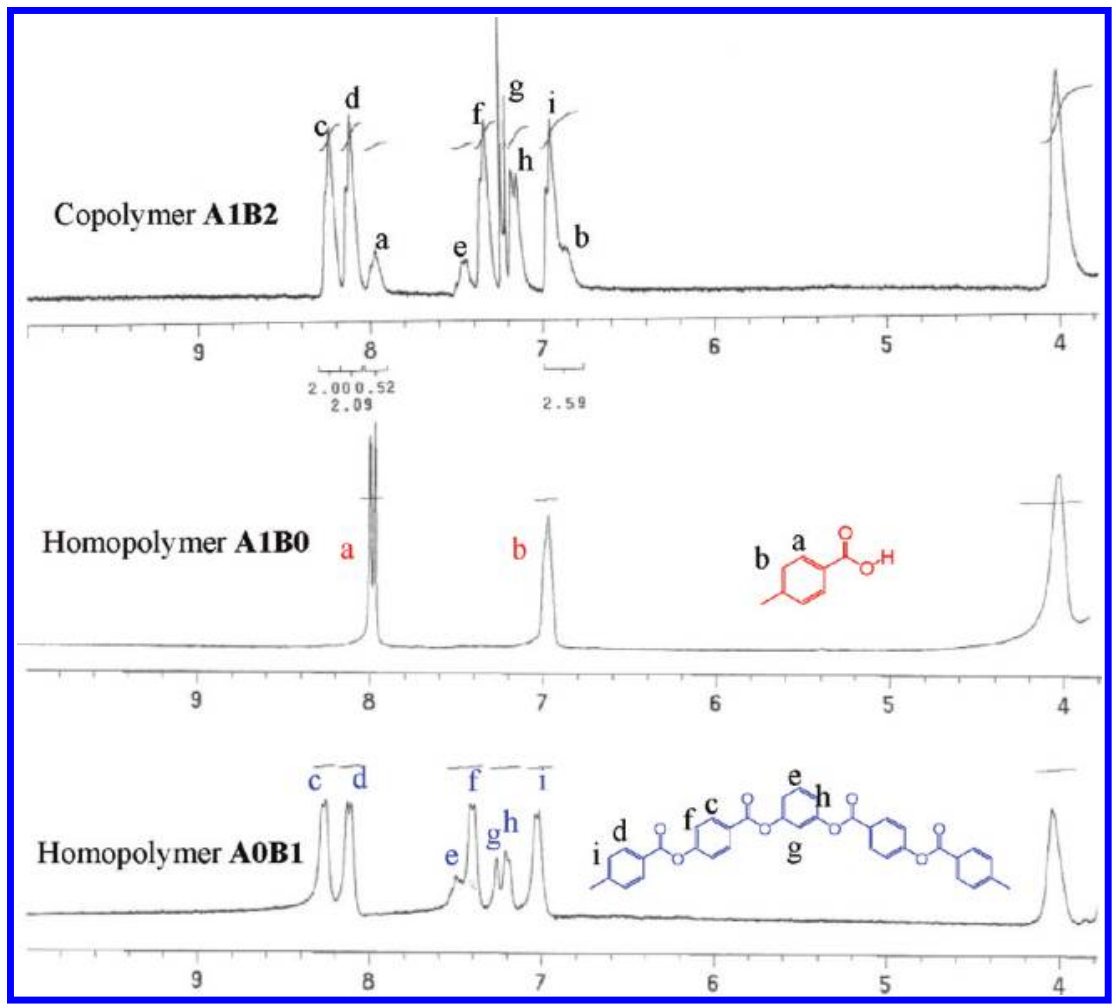

Figure 3. NMR patterns of side-chain polymers A1B2 (copolymers), A1B0 (homopolymers), and A0B1 (homopolymers).

properties influenced by the molar ratios of bent-core covalentand H-bonded structures in bent-core side-chain polymer and H-bonded polymer complexes were mainly investigated, and their mesomorphic and electro-optical properties were examined and characterized by polarizing optical microscopy (POM), differential scanning calorimetry (DSC), powder X-ray diffraction (XRD), and electro-optical (EO) switching current experiments.

Synthesis and Characterization of Polymers. In order to identify the polymers (or copolymers) and the molar ratio of copolymers, all side-chain polymers $\mathbf{A} \boldsymbol{m} \mathbf{B} \boldsymbol{n}$ and monomers $\mathbf{A}$ and $\mathbf{B}$ were investigated by ${ }^{1} \mathrm{H}$ NMR measurements. As shown in Figure 2, both monomers $\mathbf{A}$ and $\mathbf{B}$ possessed the resonant peaks in the chemical shift range of 5.7-6.4 ppm belonging to the signal of acryl groups, which disappeared in the corresponding homopolymers A1B0 and A0B1 (see Figure 3). Meanwhile, the resonant peaks in the range of $6.6-8.5 \mathrm{ppm}$ (attributed to the aromatic rings) are contributed from the benzoic acid groups of structure $\mathbf{A}$ (peaks a and $b$ ) and the five phenyl rings of structure $\mathbf{B}$ (peaks c, d, e, f, 


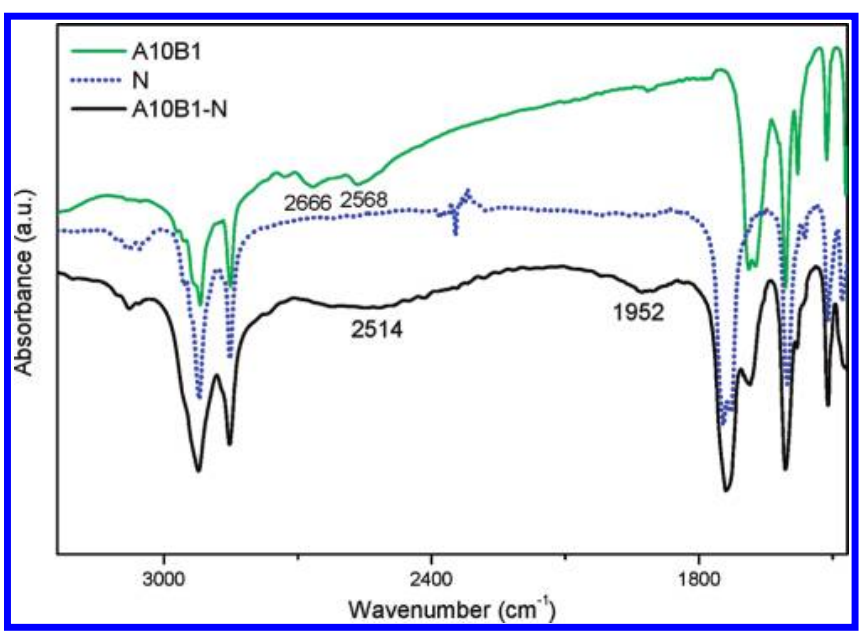

Figure 4. IR spectra of polymer A10B1, pyridyl H-acceptor N, and polymer complex A10B1-N.

$\mathrm{g}, \mathrm{h}$, and i). To recognize the molar $(\boldsymbol{m} / \boldsymbol{n})$ ratios of copolymers, the integral values of ${ }^{1} \mathrm{H}$ NMR peaks from structures $\mathbf{A}$ and $\mathbf{B}$ in each copolymers were calculated the integral values of NMR peaks $\mathrm{a}-\mathrm{b}$ (from structure $\mathbf{A}$ ) along with paeks $\mathrm{c}-\mathrm{d}$ and $\mathrm{i}$ (from structure $\mathbf{B}$ ). Based on this calculating way, copolymers A16B1, A10B1, A4B1, A1B2, A1B5, and A1B13 and homopolymers $\mathbf{A} \mathbf{1 B 0}$ and $\mathbf{A 0 B} 1$ were characterized. In addition, the number-average molecular weights $\left(M_{\mathrm{n}}\right)$ and polydispersity index (PDI) values of all polymers were acquired by GPC experiments as shown in Table 1, where the PDI values were in the range of $1.13-1.29$ and $M_{\mathrm{n}}$ values were in the range of $(5.1-12.7) \times 10^{3}$. The $M_{\mathrm{n}}$ values were increased at higher values of $\boldsymbol{n}$ (part $\mathbf{B}$ ratio) due to the higher molecular weight of part $\mathbf{B}$.

IR Characterization. The existence and stability of $\mathrm{H}-$ bonds in polymer complexes were characterized by IR spectra, and the IR spectra of H-donor polymer A10B1 (with acidic groups) and pyridyl $\mathrm{H}$-acceptor $(\mathbf{N})$ were compared with that of complex copolymer A10B1-N to examine the existence of $\mathrm{H}$-bonds as shown in Figure 4. In contrast to the $\mathrm{O}-\mathrm{H}$ bands of pure A10B1 at 2666 and $2568 \mathrm{~cm}^{-1}$, the weaker $\mathrm{O}-\mathrm{H}$ band observed at 2514 and $1952 \mathrm{~cm}^{-1}$ in complex A10B1-N was indicative of hydrogen bonding between the pyridyl group of $\mathbf{N}$ and acidic group of $\mathbf{A}$. On the other hand, a $\mathrm{C}=\mathrm{O}$ stretching vibrations appeared at $1728 \mathrm{~cm}^{-1}$ (shoulder) and $1687 \mathrm{~cm}^{-1}$ in complex A10B1-N, which showed that the carbonyl group is in a less associated state than in pure A10B1 with weaker $\mathrm{C}=\mathrm{O}$ stretching vibrations appeared at 1687 and $1671 \mathrm{~cm}^{-1} \cdot 25,35$ The results suggested that H-bonds of polymer complex A10B1-N are formed between copolymer A10B1 and $\mathrm{H}$-acceptor $\mathbf{N}$. In addition, the other polymer complexes were also confirmed to exhibit H-bonded frameworks as polymer complex A10B1-N, so the supramolecular structures were established in all polymer complexes.

Mesophasic and Thermal Properties. (1) Side-Chain Polymers $\mathbf{A} \boldsymbol{m} \mathbf{B} \boldsymbol{n}$. In order to understand the influence of the molar ratio of covalent-bonded bent-core units on the mesomorphic, molecular stacking, and thermal properties, side-chain polymers $\mathbf{A} \boldsymbol{m} \mathbf{B} \boldsymbol{n}$ were investigated by POM, DSC, and XRD measurements. The thermal properties and phase behaviors of side-chain polymers $\mathbf{A} \boldsymbol{m} \mathbf{B} \boldsymbol{n}$ are illustrated in Figure $7 \mathrm{a}$ and Table 2. Polymers A1B0, A16B1, and A10B1 with higher $\boldsymbol{m} / \boldsymbol{n}$ molar ratios (lower densities of covalent-bonded bent-core units) possessed the tilted smectic (SmC) phases, which were verified by POM to show the enantiotropic schlieren texture and grainy domain. For
Table 2. Phase Transition Temperatures and Enthalpies of SideChain Polymers $^{a}$

\begin{tabular}{|c|c|}
\hline polymer & $\begin{array}{c}\left.\text { phase transition temperature } /{ }^{\circ} \mathrm{C} \text { [enthalpy } / \mathrm{kJ} / \mathrm{g}\right] \\
\text { heating (top) } / \text { cooling (bottom) }\end{array}$ \\
\hline A1B0 & $\begin{array}{l}\mathbf{K} 71.2[1.3] \mathbf{K}^{\prime} 96.3[1.7] \mathbf{S m C}_{\mathbf{1}} 162.2[22.4] \mathbf{I} \\
\mathbf{I} 155.1[-27.5] \mathbf{S m C}_{\mathbf{1}} 76.2[-4.5] \mathbf{K}\end{array}$ \\
\hline A16B1 & $\begin{array}{l}\text { K } 141.2[1.3] \mathbf{S m C}_{\mathbf{1}} 159.7[10.4] \mathbf{I} \\
\text { I } 153.6[-12.9] \mathbf{S m C}_{\mathbf{1}} 140.9[-1.8] \mathbf{K}\end{array}$ \\
\hline $\mathrm{A} 10 \mathrm{~B} 1$ & $\begin{array}{l}\text { K } 140.2[6.4] \mathbf{S m C}_{\mathbf{1}} 154.3[1.7] \mathbf{I} \\
\text { I } 153.3[-7.6]^{b} \mathbf{S m C}_{\mathbf{1}} 138.7^{b} \mathbf{K}\end{array}$ \\
\hline A4B1 & $\begin{array}{l}\text { K } 112.3[0.6] \mathbf{N} 129.8[4.5] \mathbf{~ I} \\
\text { I } 129.7[-3.6] \mathbf{~ N ~} 105.3[-1.0] \mathbf{K}\end{array}$ \\
\hline A1B2 & $\begin{array}{l}\mathbf{K} 71.3[3.5] \mathbf{S m C}_{\mathbf{2}} 96.0[5.7] \mathbf{I} \\
\mathbf{I} 90.1[-2.8] \mathbf{S m C}_{\mathbf{2}} 74.3[-0.7] \mathbf{K}^{\prime} 59.2[-1.4] \mathbf{K}\end{array}$ \\
\hline A1B5 & $\begin{array}{l}\mathbf{K} 75.9[6.9] \mathbf{S m C}_{2} 98.8[2.5] \mathbf{I} \\
\mathbf{I} 88.7[-4.69] \mathbf{S m C}_{2} 74.8[-4.5] \mathbf{K}\end{array}$ \\
\hline A1B13 & $\begin{array}{l}\text { K } 120.4[18.5] \mathbf{S m C}_{2} 140^{c} \mathbf{I} \\
\text { I } 135^{c} \mathbf{S m C}_{2} 115.4[-15.3] \mathbf{K}\end{array}$ \\
\hline A0B1 & $\begin{array}{l}\mathbf{K} 136.3[23.5] \mathbf{S m C}_{\mathbf{2}} 150^{c} \mathbf{I} \\
\text { I } 148^{c} \mathbf{S m C}_{\mathbf{2}} 130[-19.4] \mathbf{K}\end{array}$ \\
\hline
\end{tabular}

${ }^{a}$ The phase transitions were measured by DSC at the second cooling scan with a cooling rate of $5^{\circ} \mathrm{C} \mathrm{min}{ }^{-1}$. I = isoptropic state; $\mathrm{N}=$ nematic phase; $\mathrm{SmC}_{1}$ and $\mathrm{SmC}_{2}=$ tilted smectic phases; $\mathrm{K}=$ crystalline state. ${ }^{b}$ Means the enthalpy values of two cover transition peaks. ${ }^{c}$ Means the temperature data is observed in POM only. Phase transitions of monomer A was obtained as I 106.4 [20.6] SmC 55.4 [8.59] K. Phase transition of monomer B was obtained as I $90.3[34.8] \mathbf{K}$.

instance, the schlieren texture and grainy domain of polymers A1B0 and A10B1 are demonstrated in parts a and $\mathrm{b}$ of Figure 5, respectively. However, polymer A4B1 revealed a nematic phase in both heating and cooling processes, and the POM texture of polymer A4B1 is shown in Figure 5c. Regarding the mesophases of polymers A1B2, A1B5, A1B13, and A0B1 with lower $\boldsymbol{m} / \boldsymbol{n}$ molar ratios (higher densities of covalent-bonded bent-core units), the same enantiotropic smectic phase (SmC) was obtained, where one of the POM texture of A1B13 is shown in Figure 5d.

Comparing the phase transition temperatures of all sidechain polymers $\mathbf{A} \boldsymbol{m} \mathbf{B} \boldsymbol{n}$, homopolymers A1B0 and A0B1 revealed the highest isotropization temperatures for polymers $\mathbf{A} \boldsymbol{m} \mathbf{B} \boldsymbol{n}$ with higher and lower $\boldsymbol{m} / \boldsymbol{n}$ molar ratios (lower and higher densities of covalent-bonded bent-core units), respectively. Higher isotropization temperatures of homopolymers A1B0 and A0B1 indicated that the tighter molecular stacking of intermolecular $\mathrm{H}$-bonded linear cores or bent cores in homopolymeric systems, which also suggested that the looser molecular stackings were formed in copolymers due to the disorder arrangements of both H-bonded linear cores and covalent-bonded bent cores. Especially, copolymer A4B1 reached the largest randomness to lose the lamellar packings for both $\mathrm{H}$-bonded linear cores and covalent-bonded bent cores, and the nematic phase was preferred instead. Hence, three cartoon diagrams are drawn in Figure 6 to explain possible intermolecular arrangements in polymers AmBn. Based on the molar ratios of bent-core units, polymers A1B0, A16B1, and A10B1 with the high density of benzoic acidic groups displayed the smectic stacking by the intermolecular acidic $\mathrm{H}$-bonds (with $\mathrm{H}$-bonded cross-linking structures) as shown in Figure 6a, and the stacking order was reduced by decreasing $\boldsymbol{m} / \boldsymbol{n}$ molar ratio. As $\boldsymbol{m} / \boldsymbol{n}$ ratio reached $4 / 1$ (polymer A4B1), the acidic H-bonded linear cores (H-bonded cross-links) would be separated into a more random stacking by the introduction of covalent-bonded bent-core unit $\mathbf{B}$ as shown in Figure $6 \mathrm{~b}$. Afterward, to the other extreme of more covalent-bonded bent-core units (B), polymers A1B2, A1B5, A1B13, and A0B1 demonstrated another smectic arrangement due to 

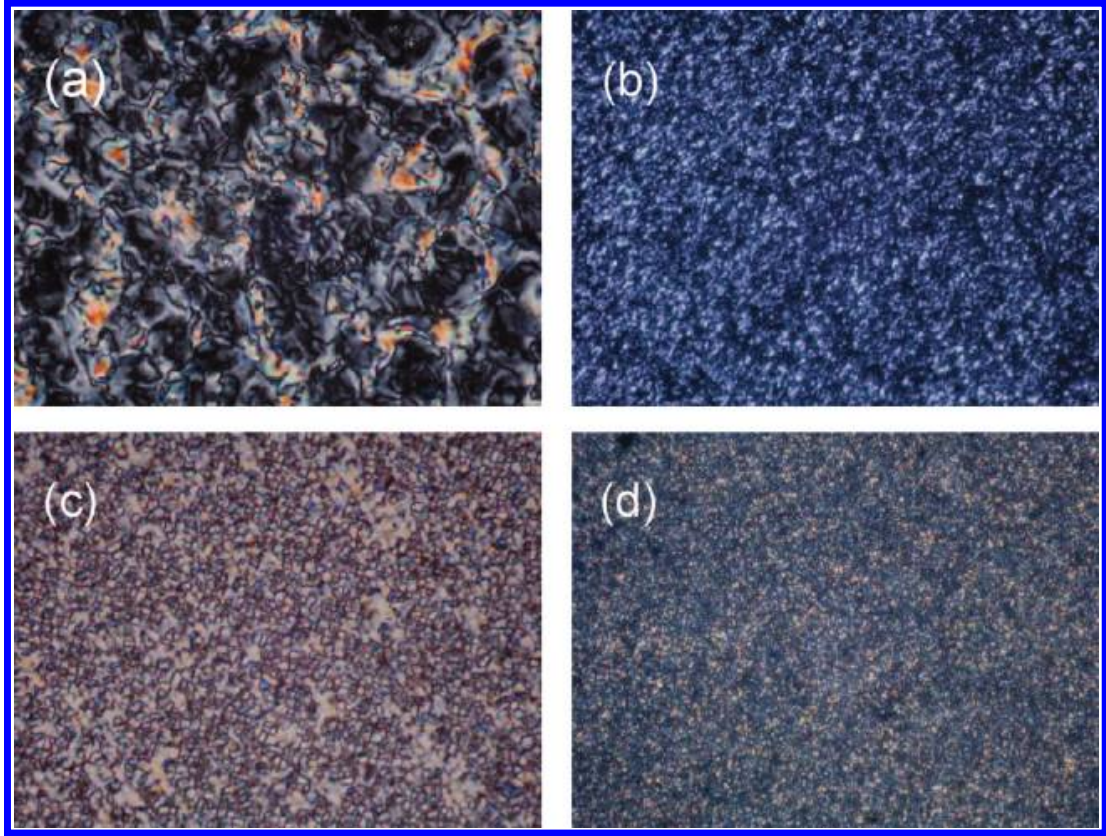

Figure 5. POM textures at the cooling process: (a) the tilted smectic phase with schlieren texture of polymer $\mathbf{A} 1 \mathbf{B} 0$ at $150^{\circ} \mathrm{C}$; (b) the tilted smectic phase with grainy domain of polymer $\mathbf{A} 10 \mathbf{B} 1$ at $150^{\circ} \mathrm{C}$; (c) the nematic phase with schlieren texture of polymer $\mathbf{A} 4 \mathbf{B} 1$ at $125^{\circ} \mathrm{C}$; (d) the tilted smectic phase with grainy domain of polymer $\mathbf{A} 1 \mathbf{B} 13$ at $130^{\circ} \mathrm{C}$.

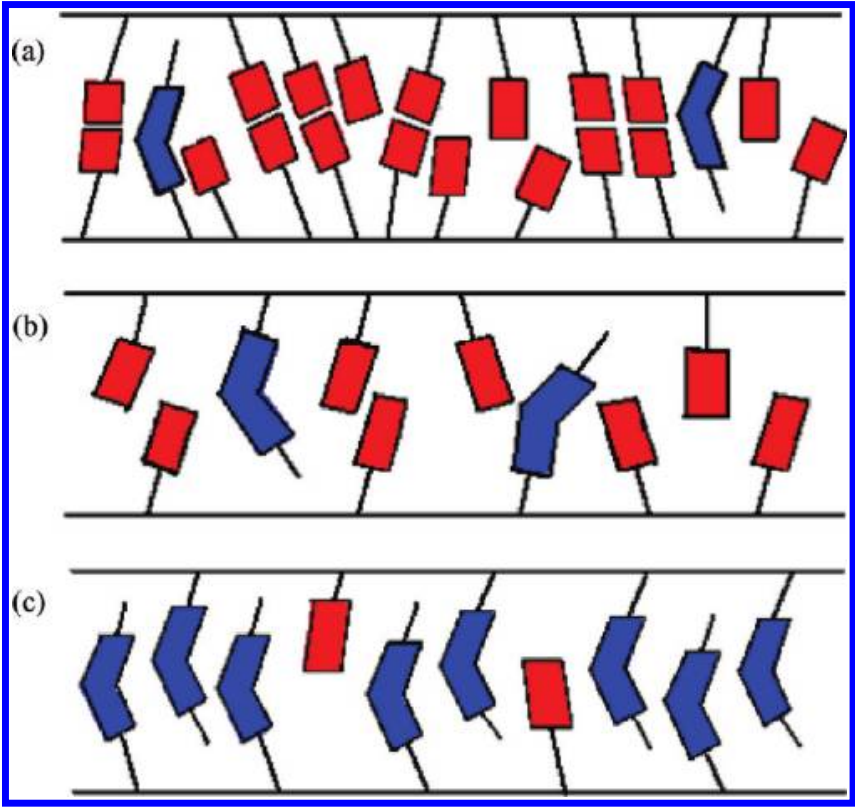

Figure 6. Cartoon diagrams of possible intermolecular arrangements of (a) polymers A1B0, A16B1, and A10B1 with larger $\boldsymbol{m} / \boldsymbol{n}$ molar ratios mainly contributed from the self $\mathrm{H}$-bonded acidic dimers, (b) polymer A4B1 with a medium $\boldsymbol{m} / \boldsymbol{n}$ molar ratio, and (c) polymers A1B2, A1B5, $\mathbf{A} 1 \mathrm{~B} 13$, and A0B1 with smaller $\boldsymbol{m} / \boldsymbol{n}$ molar ratios mainly contributed from the major component of covalent-bonded bent cores.

the major intermolecular stackings of bent-core units (see Figure 6c).

(2) Bent-Core Side-Chain Polymer Complexes AmBn-N. The influence of molar ratios of bent-core covalent- and $\mathrm{H}$-bonded units on the mesomorphic, molecular stacking, and thermal properties of bent-core side-chain polymer complexes $\mathbf{A} \boldsymbol{m} \mathbf{B} \boldsymbol{n}-\mathbf{N}$ were also investigated by POM, DSC, and XRD measurements. The thermal properties and phase behaviors of bent-core side-chain polymer complexes $\mathbf{A} \boldsymbol{m} \mathbf{B} \boldsymbol{n}$ $\mathbf{N}$ are illustrated in Figure $7 \mathrm{~b}$ and Table 3. According to Figure S1 of the Supporting Information, compound S12

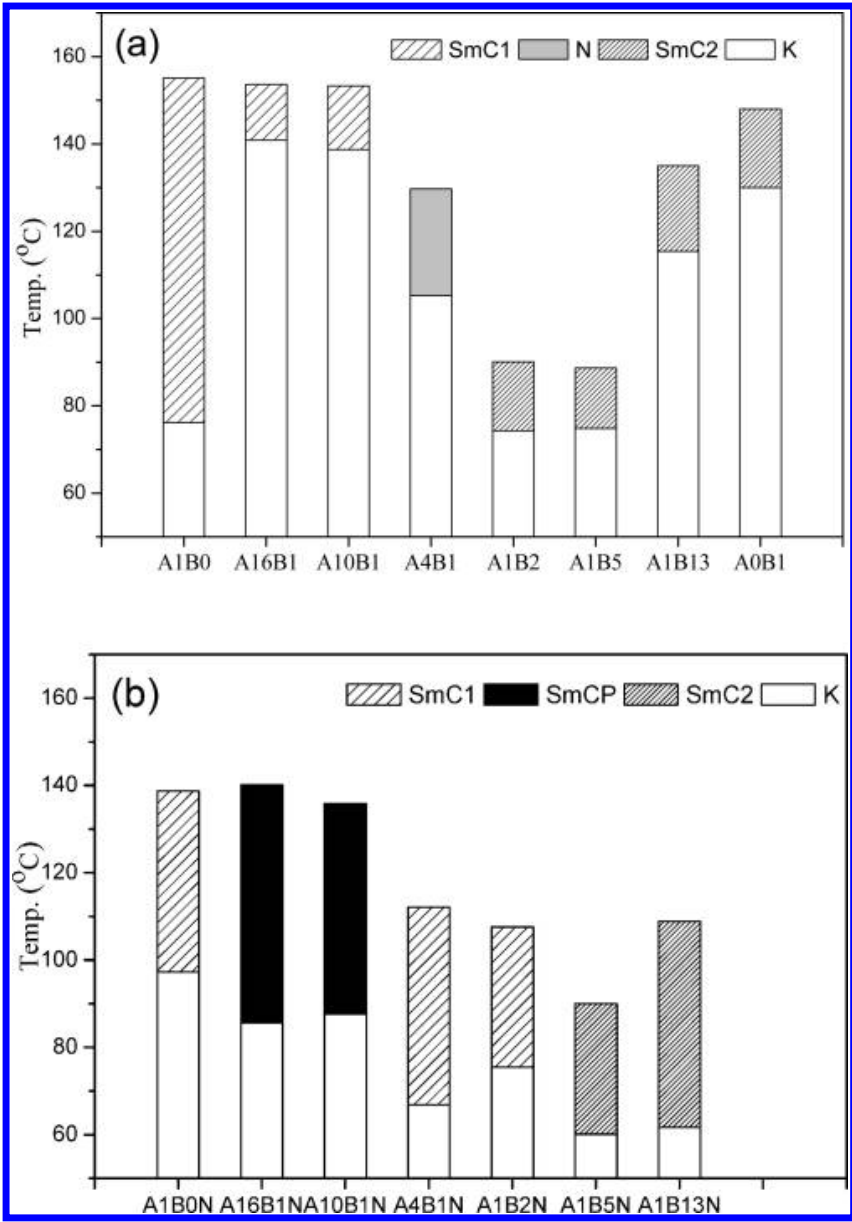

Figure 7. Phase diagrams (upon second cooling) of (a) side-chain polymers $\mathbf{A} \boldsymbol{m} \mathbf{B} \boldsymbol{n}$ and (b) bent-core side-chain polymer complex $\mathrm{A} m \mathrm{~B} n-\mathrm{N}$.

and supramolecular analogue H12 (H-bonded complex) both exhibited the $\mathrm{SmCP}$ phase, so bent-core side-chain 
Table 3. Phase Transition Temperatures and Enthalpies of Bent-Core Side-Chain Polymer Complexes ${ }^{a}$

\begin{tabular}{|c|c|}
\hline polymer complex & $\begin{array}{c}\text { phase transition temperature } /{ }^{\circ} \mathrm{C} \\
\text { [enthalpy } / \mathrm{kJ} / \mathrm{g} \text { ] heating (top)/cooling (bottom) }\end{array}$ \\
\hline A1B0-N & $\begin{array}{l}\mathbf{K} 125.6[43.3] \mathbf{S m C}_{\mathbf{1}} 158.0[2.5] \mathbf{I} \\
\mathbf{I} 138.7[1.9] \mathbf{S m C}_{\mathbf{1}} 97.3[36.8] \mathbf{~}\end{array}$ \\
\hline A16B1-N & $\begin{array}{l}\text { K } 80.0[2.7] \mathbf{K}^{\prime} 112.7[13.3] \mathbf{S m C P} 145.5[15.0] \mathbf{I} \\
\mathbf{I} 140.1[-12.2] \mathbf{S m C P} 85.6[-1.8] \mathbf{K}^{\prime} 59.4[-9.0] \mathbf{K}\end{array}$ \\
\hline A10B1-N & $\begin{array}{l}\mathbf{K} 85.4[2.8] \mathbf{K}^{\prime} 116.1[18.7] \mathbf{S m C P} 143.0[3.2] \mathbf{I} \\
\mathbf{I} 135.8[-17.0] \mathbf{S m C P} 87.7[-2.3] \mathbf{K}^{\prime} 66.7[-10.6] \mathbf{K}\end{array}$ \\
\hline A4B1-N & $\begin{array}{l}\text { K } 78.5[5.4] \mathbf{S m C}_{\mathbf{1}} 117.3[11.4] \mathbf{I} \\
\mathbf{I} 112.1[-8.4] \mathbf{S m C}_{\mathbf{1}} 66.8[-2.7] \mathbf{K}\end{array}$ \\
\hline A1B2-N & $\begin{array}{l}\text { K } 77.4[6.0] \mathbf{S m C}_{\mathbf{1}} 110.8[14.3] \mathbf{I} \\
\mathbf{I} 107.6[-7.0] \mathbf{S m C}_{\mathbf{1}} 75.5[-14.7] \mathbf{K}\end{array}$ \\
\hline A1B5-N & $\begin{array}{l}\text { K } 79.9[9.9] \mathbf{S m C}_{2} 95.7[17.1] \mathbf{I} \\
\mathbf{I} 90.0[-19.7] \mathbf{S m C}_{2} 60.1[-9.0] \mathbf{K}\end{array}$ \\
\hline A1B13-N & $\begin{array}{l}\mathbf{K} 75.9[1.6] \mathbf{S m C}_{2} 115.2[12.9] \mathbf{I} \\
\mathbf{I} 108.9[-13.9] \mathbf{S m C}_{2} 61.7[-1.2] \mathbf{K}\end{array}$ \\
\hline
\end{tabular}
[36.4] K.

polymer complexes $\mathbf{A} \boldsymbol{m} \mathbf{B} \boldsymbol{n}-\mathbf{N}$ via the copolymerization of these two units (S12 and H12) were prepared and surveyed for the generation of the SmCP phase. However, because of the addition of acrylate termini in their similar structures, $\mathbf{B}$ and $\mathbf{A}-\mathbf{N}$ units did not possess any SmCP phase, where the phase transition temperatures of monomers $\mathbf{A}$ and $\mathbf{B}$ along with complex A-N were obtained as A: I $106.4{ }^{\circ} \mathbf{C ~ S m C ~}$ $55.4{ }^{\circ} \mathrm{C} \mathrm{K}$, B: I $90.3{ }^{\circ} \mathrm{C} \mathrm{K}$, and A-N: I $76.7^{\circ} \mathrm{C} \mathrm{K}$, respectively.

In comparison with side-chain polymers $\mathbf{A} \boldsymbol{m} \mathbf{B} \boldsymbol{n}$, bent-core side-chain polymer complexes $\mathbf{A} \boldsymbol{m} \mathbf{B} \boldsymbol{n}-\mathbf{N}$ have lower isotropization temperatures due to their $\mathrm{H}$-bonded pendants assembled by pyridyl and acidic groups, which have less intermolecular acidic $\mathrm{H}$-bonds (with less $\mathrm{H}$-bonded crosslinks). Therefore, the novel enantiotropic polar smectic (SmCP) phase was surprisingly generated in some compositions of bent-core side-chain polymer complexes $\mathbf{A} \boldsymbol{m} \mathbf{B} \boldsymbol{n}-\mathbf{N}$. Regarding the mesophasic types, the enantiotropic tilted smectic phase was observed in polymer complexes A1B0N, A4B1-N, A1B2-N, A1B5-N, and A1B13-N, and the enantiotropic polar smectic $(\mathrm{SmCP})$ phase was achieved in polymer complexes A16B1-N and A10B1-N. The mesophasic textures were observed by POM experiments; for instance, polymer complex A10B1-N revealed the polar smectic phase with a fanlike texture in Figure $8 \mathrm{a}$, and polymer complex A1B13-N exhibited the tilted smectic $(\mathrm{SmC})$ phase with a grainy domain in Figure $8 \mathrm{~b}$, which were the characteristics of the tilted smectic phases.

With regard to the variation of mesophasic transition temperatures of polymer complexes $\mathbf{A} \boldsymbol{m} \mathbf{B} \boldsymbol{n}-\mathbf{N}$, the isotropization temperatures and mesophasic ranges were reduced as the $\boldsymbol{m} / \boldsymbol{n}$ molar ratio decreased (except A1B13-N). Side-chain copolymers $\mathbf{A} \boldsymbol{m} \mathbf{B} \boldsymbol{n}$ with higher $\boldsymbol{m} / \boldsymbol{n}$ ratios possessed more $\mathrm{H}$-donor groups exhibited more extensive mesophasic ranges and higher isotropization temperatures, which indicated that the acidic $\mathrm{H}$-bonded linear-cores (H-bonded crosslinks) would extend and stabilize the mesophase. However, because of the intermolecular acidic H-bonds (with $\mathrm{H}$-bonded cross-linking structures) of side-chain copolymers $\mathbf{A} \boldsymbol{m} \mathbf{B} \boldsymbol{n}$ being replaced with side-chain $\mathrm{H}$-bonded pendants of the analogous polymer complexes $\mathbf{A} \boldsymbol{m} \mathbf{B} \boldsymbol{n}-\mathbf{N}$, bent-core sidechain polymer complexes $\mathbf{A} \boldsymbol{m} \mathbf{B} \boldsymbol{n}-\mathbf{N}$ with higher $\boldsymbol{m} / \boldsymbol{n}$ molar ratios did not exhibit more extensive mesophasic ranges but still possessed higher isotropization temperatures. Compared with side-chain copolymers $\mathbf{A} \boldsymbol{m} \mathbf{B} \boldsymbol{n}$, the corresponding polymer complexes $\mathbf{A} \boldsymbol{m} \mathbf{B} \boldsymbol{n}-\mathbf{N}$ generally exhibited more

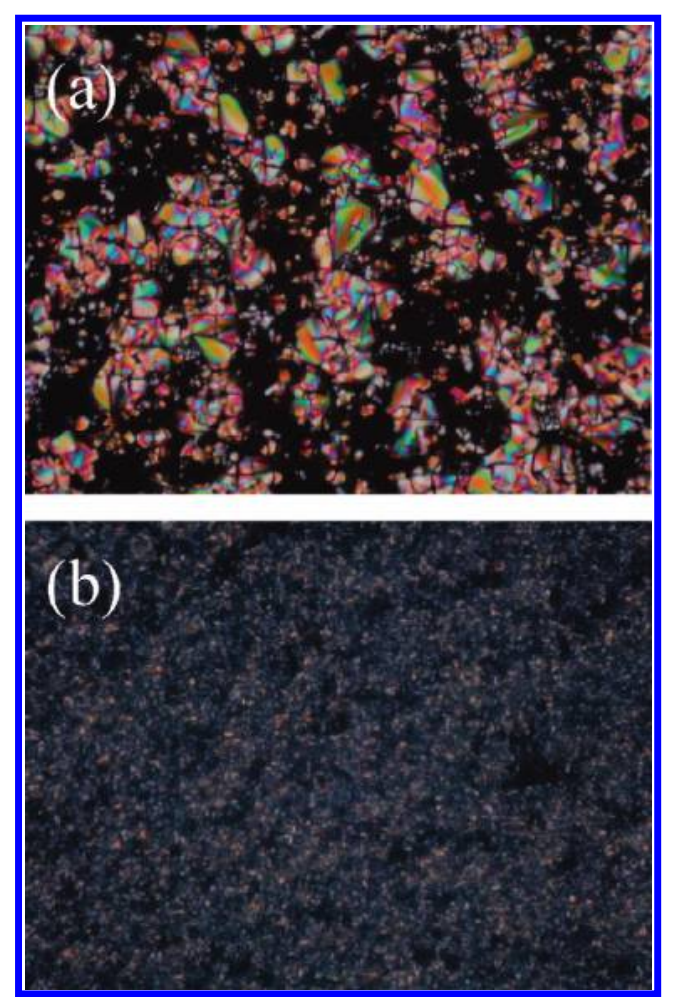

Figure 8. POM textures at the cooling process: (a) the polar smectic phase with fanlike texture of polymer complex A10B1-N at $130{ }^{\circ} \mathrm{C}$; (b) the tilted smectic phase with grainy domain of polymer complex A1B13$\mathbf{N}$ at $85{ }^{\circ} \mathrm{C}$.

extensive mesophasic ranges and lower transition temperatures, except polymer complexes A1B2-N and A1B5-N. In addition, the nematic phase in copolymer $\mathbf{A 4 B 1}$ was replaced by a tilted smectic phase in polymer complex A4B1-N. More excitingly, the polar smectic phase (the switching current behaviors will be demonstrated later) was achieved in polymer complexes A16B1-N and A10B1-N, though the individual components of $\mathrm{H}$-donor side-chain copolymers A16B1 and A10B1 as well as $\mathrm{H}$-acceptor $\mathbf{N}$ did not possess the $\mathrm{SmCP}$ phase (see Tables 2 and 3). Hence, it suggested that the mesomorphic and thermal properties of polymer complexes $\mathrm{A} \boldsymbol{m} \mathrm{B} n-\mathrm{N}$ were strongly dependent on the $\boldsymbol{m} / \boldsymbol{n}$ molar ratios of bent-core covalent- and $\mathrm{H}$-bonded units (i.e., $\mathbf{B}$ and A-N units, respectively), where the bent-core $\mathrm{H}$-bonded units were formed by the acidic $\mathrm{H}$-donor groups (A groups from side-chain polymers $\mathbf{A} \boldsymbol{m} \mathrm{B} n$ ) incorporated with $\mathrm{H}$-acceptor $\mathbf{N}$. Therefore, we have discovered a special technique that the construction (or stabilization) of the SmCP phase can be acquired by copolymerization of bent-core covalentand H-bonded units in side-chain polymer complexes (with proper $\boldsymbol{m} / \boldsymbol{n}$ molar ratios) from both bent-core covalent- and H-bonded monomers (i.e., B and $\mathbf{A}-\mathbf{N}$ units, respectively) without the SmCP phase (see Figure 9).

Powder XRD Analyses. (1) Side-Chain Polymers AmBn. The molecular arrangements of side-chain polymers $\mathbf{A} \boldsymbol{m} \mathbf{B} \boldsymbol{n}$ in different mesophases were investigated by XRD measurements at various temperatures upon cooling (see Figures 10 and 11). As shown in Figure 10a (also see Figures S3a of the Supporting Information), the 2D XRD pattern of polymer A16B1 at $150{ }^{\circ} \mathrm{C}$ during the cooling process revealed a diffuse peak at wide angles corresponding to a $d$-spacing value of $4.6 \AA$, which demonstrated that similar liquidlike in-plane orders with average intermolecular distances were prevalent inside the layers of bent-core units. Two single sharp peaks were observed at corresponding $d$-spacing values of 


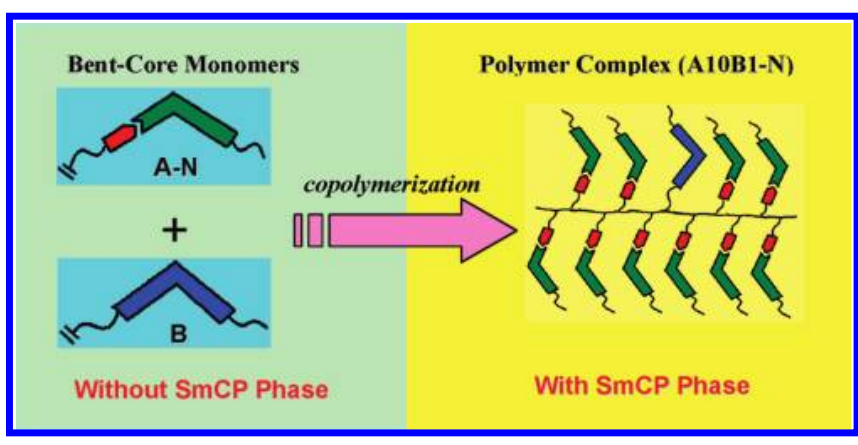

Figure 9. SmCP phase was introduced by copolymerized frameworks bearing both bent-core covalent- and H-bonded monomers (B and A-N units with proper $\boldsymbol{m} / \boldsymbol{n}$ molar ratios) without the SmCP phase.

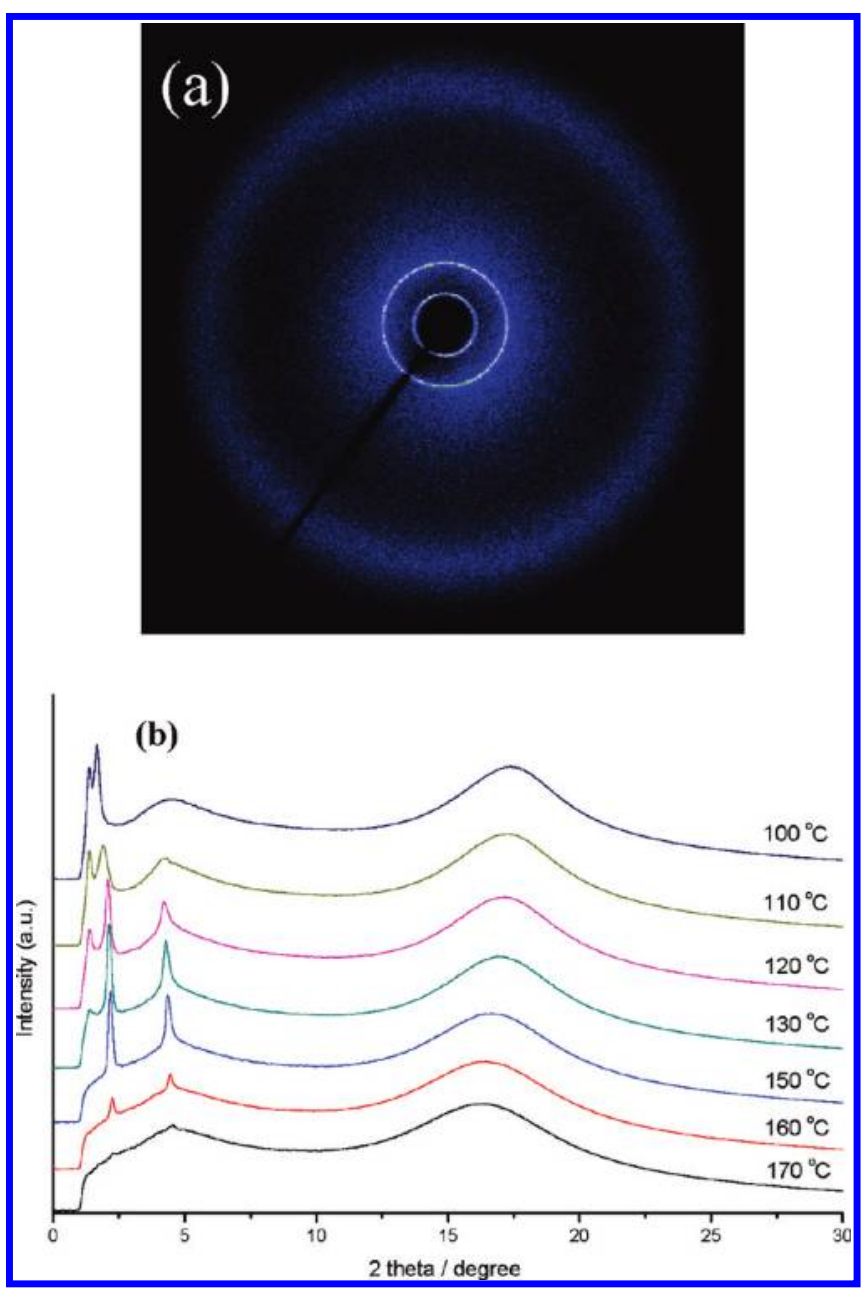

Figure 10. Powder X-ray data of polymer A16B1: (a) 2D pattern in the tilted smectic phase $\left(150^{\circ} \mathrm{C}\right)$; (b) powder X-ray diffraction intensity against angle profiles at various temperatures upon cooling from the isotropic to crystalline phases.

$d_{1}=35.4 \AA$ and $d_{2}=17.7 \AA$ in small angle regions, where the longest $d$-spacing value $d_{1}$ was indexed as (001). The $d$-spacing value $\left(d_{1}\right)$ is shorter than the theoretical coplanar molecular length $(L)$ (about $47 \AA$ ) of self $\mathrm{H}$-bonded benzoic acidic dimer to indicate the tilted smectic arrangement. In addition, temperature-dependent XRD results of polymer A16B1 were also provided in Figure 10b. Two sharp peaks appeared during the cooling process from the isotropic to mesophasic states. An additional peak with a corresponding $d$-spacing value $(\sim 46 \AA)$ similar to its theoretical molecular length was obtained as the temperature was equivalent to or
Table 4. Powder XRD Data of Side-Chain Polymers

\begin{tabular}{lclc}
\hline polymer & cooling temp $\left({ }^{\circ} \mathrm{C}\right)$ & $2 \theta(\mathrm{deg})$ & $d$-spacing $(\AA)$ \\
\hline A1B0 & 140 & 2.24 & 34.1 \\
& & 4.47 & 17.1 \\
A16B1 & 150 & 2.16 & 35.4 \\
& & 4.33 & 17.7 \\
A10B1 & 140 & 2.12 & 36.1 \\
& & 4.25 & 18.0 \\
A4B1 & 120 & $4.37(\mathrm{br})$ & 17.5 \\
A1B2 & 90 & 2.06 & 37.1 \\
& & 2.70 & 28.3 \\
& & 3.82 & 20.0 \\
A1B5 & \multirow{2}{*}{90} & 4.09 & 18.7 \\
& & 2.00 & 38.2 \\
& & 2.83 & 27.0 \\
A1B13 & \multirow{2}{*}{120} & 3.78 & 20.2 \\
& & 6.04 & 12.7 \\
& & 2.04 & 37.5 \\
A0B1 & 3.08 & 24.8 \\
& \multirow{2}{*}{140} & 3.80 & 20.1 \\
& & 4.45 & 17.2 \\
& & 2.10 & 36.4 \\
& & 3.14 & 24.3 \\
& & 3.85 & 19.9 \\
& & 4.48 & 17.1 \\
& & 5.20 & 14.7
\end{tabular}

lower than $130^{\circ} \mathrm{C}$, and the orthogonal arrangement of the crystalline phase or highly ordered smectic phase was generated. Polymers A1B0 and A10B1 illustrated similar XRD results as shown in the Supporting Information (see Figures S2a and S4a) to indicate the analogous smectic mesophase.

Polymer A4B1 did not obtain any sharp diffraction peak at small angle regions in the mesophasic temperature $\left(120^{\circ} \mathrm{C}\right)$ to reveal one dimension order of nematic phase as shown in Figure S5 of the Supporting Information, but two broad peaks were observed at the corresponding $d$-spacing values of 17.1 and $4.6 \AA$. Until the temperature reaching the crystalline state $\left(100{ }^{\circ} \mathrm{C}\right)$, a $d$-spacing value of $66.5 \AA$ was produced to indicate the orthogonal arrangement of the crystalline phase or highly ordered smectic phase. The powder XRD results of polymer A4B1 in various temperatures was also provided in Figure S5a of the Supporting Information to reveal its phase transition in the cooling process from the isotropic to crystalline states.

As the shown pattern of polymer A1B13 at $120{ }^{\circ} \mathrm{C}$ (see Figure S8a of the Supporting Information), several sharp peaks were detected at corresponding values of $d_{1}=37.5 \AA$, $d_{2}=25.4 \AA$, and $d_{3}=19.1 \AA$ in small angle regions (along with some other undefined sharp peaks). The ratio of $d_{1}$ to $d_{3}$ was 2:3:4 to index (002), (003), and (004), and a $d$-spacing value ca. $76 \AA$ was correspondent to the essential peak indexed as (001), which might be lost due to the limitation of the XRD instrument. A broad peak was gained at the wide angle regions to account for the natural mesogenic stacking width. This similar result was reported in the literature ${ }^{17}$ to mean the long-range ordered smectic structure of $\mathrm{SmC}_{2}$. The XRD investigations of polymer A1B13 at various temperatures from the isotropic to crystalline states were performed in Figure S7a of the Supporting Information, and polymers A1B2, A1B5, and A0B1 exhibited similar XRD results with those of A1B13 in the Supporting Information (see Figures S6a, S8a, and S9).

In comparison the variation of $d$-spacing values in all side-chain polymers $\mathbf{A} \boldsymbol{m} \mathbf{B} \boldsymbol{n}$ as shown in Table 4 (also see Figures S10a of the Supporting Information), the $d$-spacing values of copolymers were larger than those of homopolymers to indicate that more tilted smectic arrangements were produced in both homopolymers A1B0 and A0B1, which 
Table 5. Powder XRD Data of Bent-Core Side-Chain Polymer Complexes

\begin{tabular}{lccc}
\hline polymer complex & cooling temp $\left({ }^{\circ} \mathrm{C}\right)$ & $2 \theta(\mathrm{deg})$ & $d$-spacing $(\AA)$ \\
\hline A1B0-N & 140 & 2.19 & 34.9 \\
A16B1-N & \multirow{2}{*}{130} & 4.43 & 17.3 \\
& & 1.77 & 43.2 \\
A10B1-N & \multirow{2}{*}{120} & 3.54 & 21.6 \\
& & 1.71 & 44.7 \\
A4B1-N & \multirow{2}{*}{100} & 3.40 & 22.5 \\
& & 1.70 & 45.0 \\
A1B2-N & \multirow{2}{*}{100} & 3.40 & 22.5 \\
& & 2.16 & 35.4 \\
A1B5-N & \multirow{2}{*}{70} & 4.32 & 17.7 \\
& & 1.76 & 43.4 \\
& & 2.65 & 28.8 \\
A1B13-N & \multirow{2}{*}{65} & 4.42 & 17.3 \\
& & 5.32 & 14.4 \\
& & 2.01 & 38.0 \\
& & 3.04 & 25.1 \\
& & 3.73 & 20.5 \\
& & 4.39 & 17.4
\end{tabular}

meant that less tilted smectic arrangement existed in copolymers with both $\mathrm{H}$-bonded acidic dimers and covalentbonded bent cores. Hence, the variations of molecular arrangements, including two kinds of tilted smectic orders (i.e., $\mathrm{SmC}_{1}$ and $\mathrm{SmC}_{2}$ ), in side-chain polymers were further identified by the XRD experiments.

(2) Bent-Core Side-Chain Polymer Complexes AmBn-N. The molecular arrangements of bent-core side-chain polymer complexes $\mathbf{A} \boldsymbol{m} \mathbf{B} \boldsymbol{n}-\mathbf{N}$ were also surveyed by XRD measurements, and their related results are illustrated in Table 5. Compared with side-chain copolymers $\mathbf{A} \boldsymbol{m} \mathbf{B} \boldsymbol{n}$, the corresponding polymer complexes $\mathbf{A} \boldsymbol{m} \mathbf{B} \boldsymbol{n}-\mathbf{N}$ generally exhibited larger $d$-spacing values (except polymer complex A1B2-N), which might be due to the coexistence of bent-core covalentand $\mathrm{H}$-bonded units in side-chain polymer complexes, and thus to have less ordered smectogenic packings and to induce lower phase transition temperatures. Similar to side-chain copolymers $\mathbf{A} \boldsymbol{m} \mathbf{B} \boldsymbol{n}$, most polymer complexes $\mathbf{A} \boldsymbol{m} \mathbf{B} \boldsymbol{n}-\mathbf{N}$ in Table 5 (also see Figures S10b of the Supporting Information) generally demonstrated larger $d$-spacing values than homopolymer complex A1B0-N (with bent-core H-bonded units only), which might have better and homogeneous packing of bent-core $\mathrm{H}$-bonded units in the tilted smectic arrangement of the homopolymer complex. Similarly, smaller $d$-spacing values were observed in $\mathbf{A 1 B 1 3}\left(d_{1}=\right.$ $37.5 \AA), \mathbf{A} 1 \mathbf{B} 13-\mathbf{N}\left(d_{1}=38.0 \AA\right)$, and A0B1 $\left(d_{1}=36.4 \AA\right)$, which might be attributed to the major component of bentcore covalent-bonded structure $\mathbf{B}$, and the influence of costacking effect contributed from bent-core H-bonded structure A-N was much less.

Polymer complex A16B1-N displayed two sharp peaks at the associated $d$-spacing values of $d_{1}=43.2 \AA$ and $d_{2}=21.6 \AA$ in small angle regions and a broad peak at the related $d$ spacing value $d=4.5 \AA$ at $130{ }^{\circ} \mathrm{C}$ (upon cooling) as shown in Figure 11a (also see Figures $\mathrm{S} 3 \mathrm{~b}$ of the Supporting Information). The largest $d$-spacing value $\left(d_{1}=43.2 \AA\right)$ is less than the theoretical length of bent-core H-bonded structure A-N (about $58 \AA$ ) to indicate the tilted smectic arrangement of polymer complex A16B1-N. The XRD results of A16B1-N at various temperatures upon cooling from the isotropic to crystalline phases are demonstrated in Figure 11b. Two sharp peaks of a characteristic smectic mesophase appeared as the temperature reached $140{ }^{\circ} \mathrm{C}$ during the cooling process. Afterward, an additional peak developed when the temperature was lower than $80^{\circ} \mathrm{C}$, where the new $d$-spacing value of $35.1 \AA$ was correspondent to the crystalline state. Polymer complexes A10B1-N,

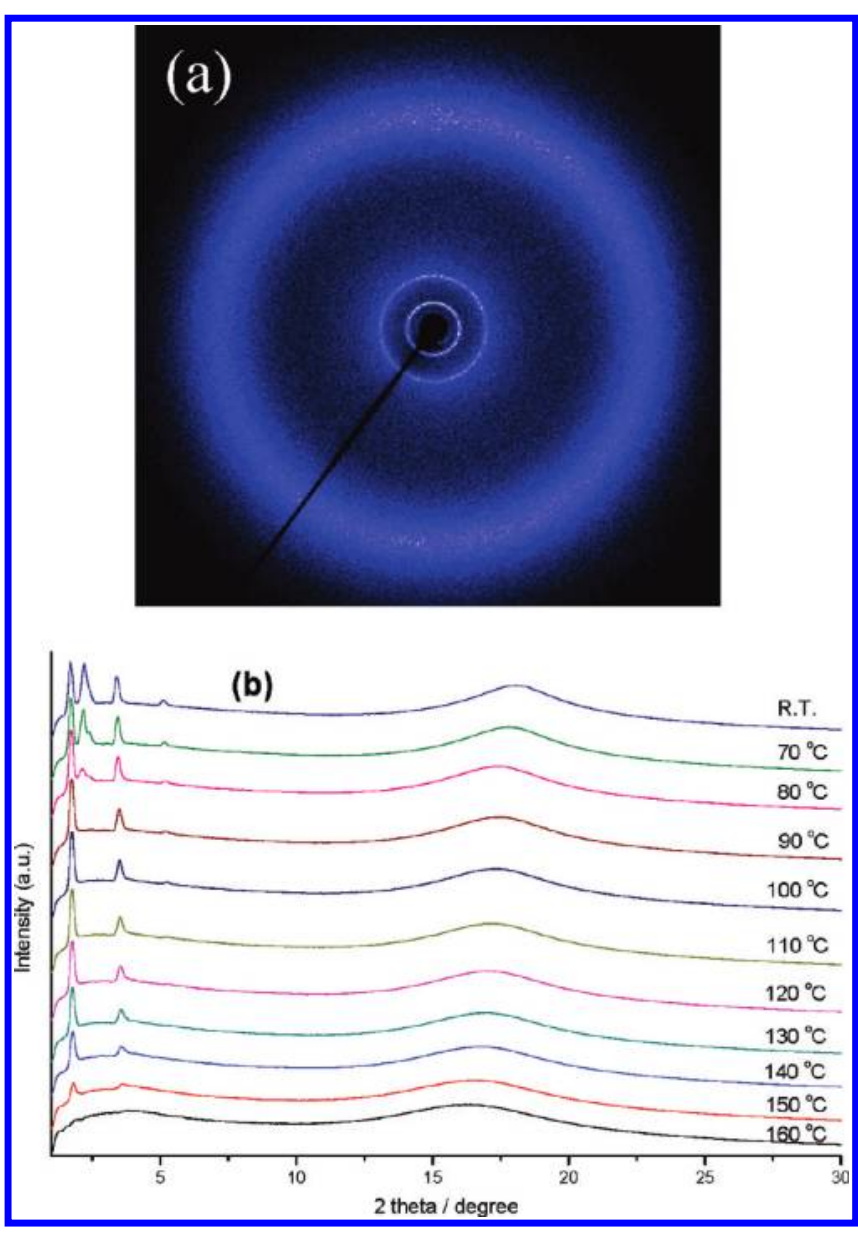

Figure 11. Powder X-ray data of polymer complex A16B1-N: (a) 2D pattern in the tilted smectic phase $\left(130^{\circ} \mathrm{C}\right)$; (b) powder X-ray diffraction intensity against angle profiles at various temperatures upon cooling from the isotropic to crystalline phases.

A4B1-N, and A1B2-N revealed similar X-ray diffraction patterns (see Figures S4b, S5b, and S6b of the Supporting Information) to indicate the analogous type of the tilted smectic mesophase. Polymer complex A1B13-N manifested the long-range ordered smectic organization in mesophasic and crystalline temperatures due to the exhibition of several sharp diffraction peaks (see Figure S7b of the Supporting Information). In addition, polymer complex A1B5-N revealed X-ray diffraction patterns (see Figure S8b of the Supporting Information) similar to that of A1B13-N, which suggested the analogous type of the tilted smectic phase in both polymer complexes.

Switching Current Behaviors and Spontaneous Polarization (Ps) of Bent-Core Side-Chain Polymer Complexes. In order to evaluate the polar switching properties of the SmCP phase in all side-chain polymers and bent-core side-chain polymer complexes, the triangular wave method ${ }^{36}$ was applied to measure the switching current behavior (i.e., the spontaneous polarization, Ps) in parallel rubbing cells with a cell gap of $4.25 \mu \mathrm{m}$. The triangular voltages were applied on all polymers and polymer complexes, and only bent-core sidechain polymer complexes A10B1-N and A16B1-N possess the switching current behaviors with specific Ps values. For instance, as shown in Figure 12a, polymer complex A10B1-N responded under a simple (continuous) triangular voltage to give a single current peak per half-period in the switching current response $\left(V_{\mathrm{pp}}=310 \mathrm{~V}\right.$ and $f=150 \mathrm{~Hz}$, at $\left.T=100^{\circ} \mathrm{C}\right)$. However, as shown in Figure 12b, the current response was separated into two repolarization peaks under the modified 


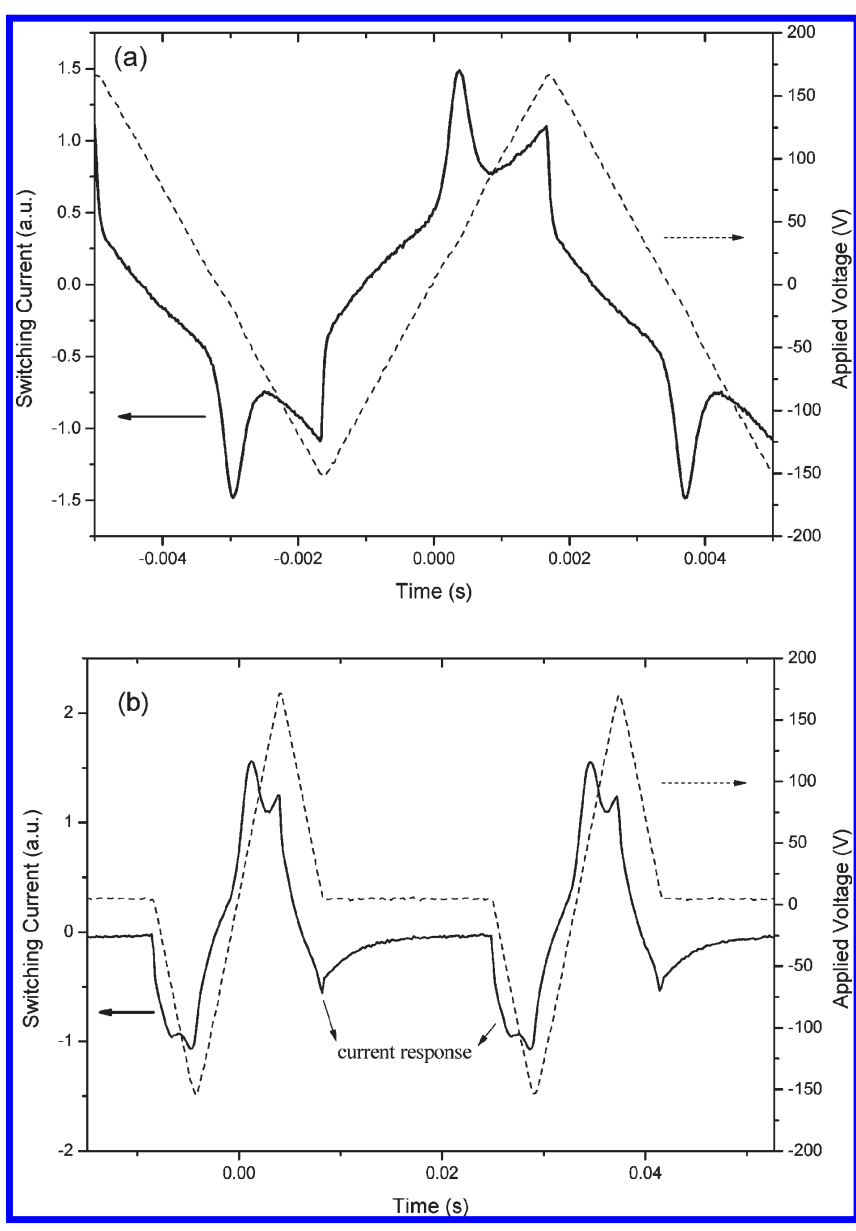

Figure 12. Switching current responses of polymer complex A10B1-N under (a) the triangular wave method (at $V_{\mathrm{pp}}=310 \mathrm{~V}, f=150 \mathrm{~Hz}$, and $T=100{ }^{\circ} \mathrm{C}$ ) and (b) the modified triangular wave method (at $V_{\mathrm{pp}}=310 \mathrm{~V}, f=30 \mathrm{~Hz}$, and $T=100^{\circ} \mathrm{C}$ ).

triangular wave (i.e., a single pulsed triangular wave, $V_{\mathrm{pp}}=$ $310 \mathrm{~V}$ and $f=30 \mathrm{~Hz}$, at $T=100{ }^{\circ} \mathrm{C}$ ), where a plateau equivalent to a triangular wave period is introduced at zero voltage, and antiferroelectric switching current responses were observed in both polymer complexes A10B1-N and A16B1-N. Here, the characteristic behavior of a sequential electric response was due to a ferroelectric state switched into an antiferroelectric ground state and back to the opposite ferroelectric state, which confirmed the $\operatorname{SmCP}_{\mathrm{A}}(\mathrm{A}=$ antiferroelectric behavior) structure of the $\mathrm{B} 2$ phase, ${ }^{35}$ and the existing $\mathrm{SmCP}_{\mathrm{A}}$ state was hidden under the continuous triangular wave measurements due to the quick exchange of $\mathrm{SmCP}_{\mathrm{F}} \rightarrow \mathrm{SmCP}_{\mathrm{A}} \rightarrow \mathrm{SmCP}_{\mathrm{F}}$.

According to the triangular wave method, the Ps values (the saturated values at high voltages) of polymer complexes A16B1-N and A10B1-N could be calculated as 15 and $60 \mathrm{nC} /$ $\mathrm{cm}^{2}$, respectively. As shown in Figure 13, the spontaneous polarization (Ps) values of polymer complex A10B1-N in the SmCP phase at various applied electric fields and temperatures were surveyed. With respect to Ps values as a function of applied voltages (at $f=60 \mathrm{~Hz}$ and $T=100{ }^{\circ} \mathrm{C}$ ) in Figure $13 \mathrm{a}$, the Ps values were steeply enhanced to reach a maximum at $V_{\mathrm{pp}} \sim 130-180 \mathrm{~V}$ by increasing the applied electric fields, and the Ps values were gradually dropped as the applied electric fields were above $V_{\mathrm{pp}} \sim 200 \mathrm{~V}$, which were reproducible for several cycles. It was speculated that the reduction of Ps values at high applied voltages was due to the weak $\mathrm{H}$-bonds of bent-core $\mathrm{H}$-bonded component $\mathbf{A}-\mathbf{N}$ in polymer complex A10B1-N, and the Ps behavior of the

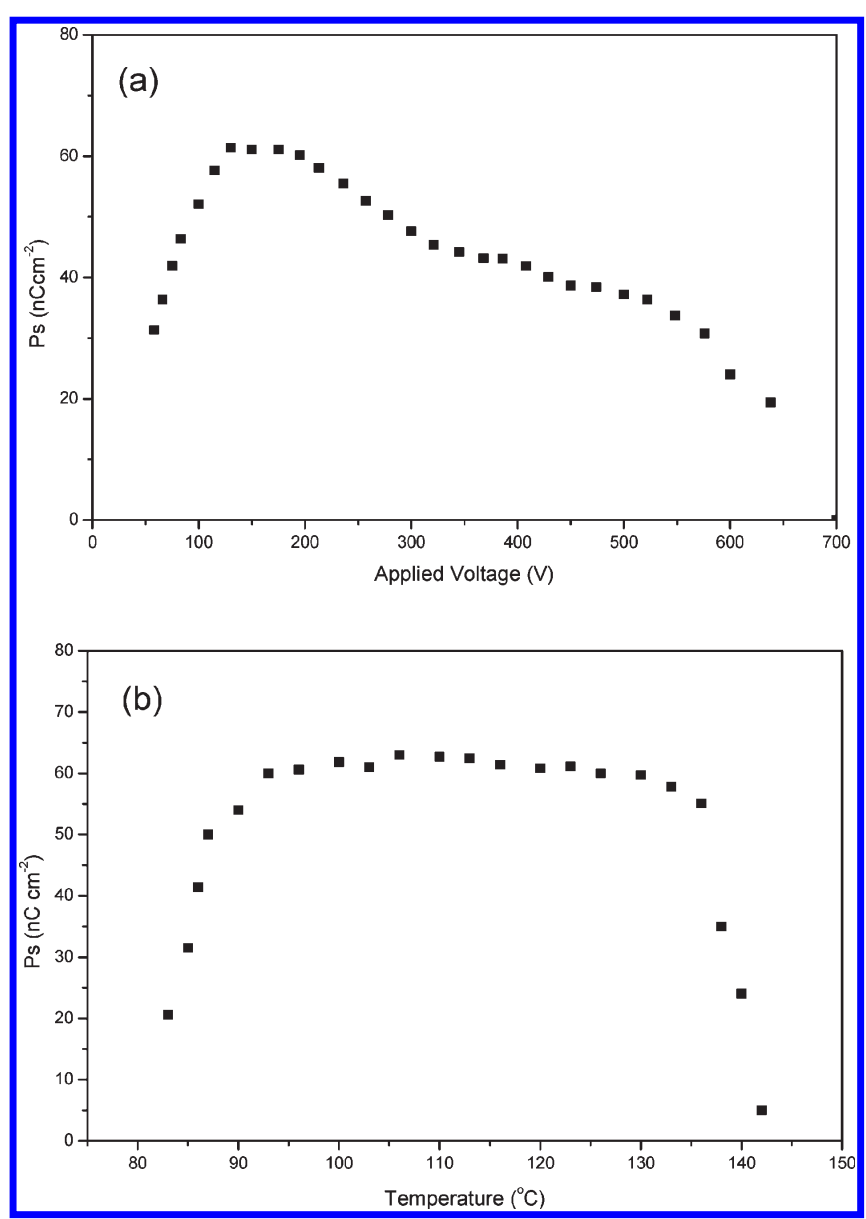

Figure 13. (a) Ps values of polymer complex A10B1-N as a function of applied voltages (at $f=60 \mathrm{~Hz}$ and $T=100^{\circ} \mathrm{C}$ ). (b) Ps values of polymer complex A10B1-N as a function of temperatures (at $V_{\mathrm{pp}}=200 \mathrm{~V}$ and $f=200 \mathrm{~Hz}$ ).

SmCP phase was mainly contributed from bent-core H-bonded component $\mathbf{A}-\mathbf{N}$ rather than from bent-core covalent-bonded component $\mathbf{B}$ (due to a large molar ratio of $\boldsymbol{m} / \boldsymbol{n}$ in A10B1-N). Hence, the novel example of bent-core side-chain polymer complex A10B1-N was evidenced to possess the voltage-sensitive switching polar behavior, which was provided by the major soft bent-core skeleton (H-bonded unit) and the minor rigid bent-core skeleton (covalent-bonded unit). In addition, as shown in Figure 13b, the Ps values of polymer complex A10B1-N at various temperatures (except the transition teperatures) were acquired as a constant value around $\mathrm{Ps}=60 \mathrm{nC} / \mathrm{cm}^{2}$ in the SmCP phase. However, the switching current phenomena were not clearly acquired in bent-core H-bonded homopolymer complex (A1B0-N), covalent-bonded homopolymer (A0B1), and the other copolymer complexes (A4B1-N, A1B2-N, A1B5-N, and A1B13-N), which indicated that the suitable A-N/B (i.e., $\boldsymbol{m} / \boldsymbol{n}$ ) molar ratio in the tilted smectic phases should be in the range of $\boldsymbol{m} / \boldsymbol{n}=16 / 1$ to $10 / 1$ to induce the polar switching behavior by the favorable molecular stackings of bent-core $\mathrm{H}$-bonded (major) and covalentbonded (minor) components with proper molar ratios of $\mathrm{m} / n$ (ca. 16/1-10/1).

\section{Conclusions}

In summary, several novel side-chain banana-shaped liquid crystalline copolymers with various molar ratio of covalent- and $\mathrm{H}$-bonded bent-core components were developed by the free 
radical polymerization, and their polymer complexes were selfassembled by appropriate molar ratios of proton donor (H-donor) polymers and pyridyl proton acceptor (H-acceptor) bent cores. The mesomorphic and electro-optical properties in the side-chain banana-shaped liquid crystalline polymers and their corresponding polymer complexes were influenced by the molar ratios of bent-core $\mathrm{H}$-bonded components effectively. The voltage-dependent antiferroelectric properties of spontaneous polarization (Ps) values in the polar smectic phase of the supramolecular side-chain banana-shaped copolymers were also first observed in this study. Several kinds of nematic and tilted smectic phases were obtained in bent-core side-chain homopolymers/copolymers and polymer complexes, which depended on the $\boldsymbol{m} / \boldsymbol{n}$ molar ratio (i.e., hydrogen- and covalent-bonded units). The nematic and tilted smectic phases were verified by XRD measurements, and the SmCP phase was further identified by the triangular wave method. Overall, the antiferroelectric behaviors of the polar semctic phase were introduced in bent-core sidechain polymer complexes $\mathbf{A} \boldsymbol{m} \mathbf{B} \boldsymbol{n}-\mathbf{N}$ by tuning the suitable $\boldsymbol{m} / \boldsymbol{n}$ molar ratios in the range of $16 / 1$ to $10 / 1$. It would be seemingly summarized that strict packing conditions between each bentcore covalent-bonded unit were present to reduce molecular oscillating, but loose packing conditions between each bent-core $\mathrm{H}$-bonded unit would induce molecular fluctuations and become dynamically unstable under electric fields. The polar switching behaviors were diminished if just only either bent-core covalentbonded or H-bonded structures were organized in the side chains of polymers. Therefore, rigid bent-core covalent-bonded components uniformly dispersed and copolymerized among soft bentcore $\mathrm{H}$-bonded ingredients in the side-chain polymers are necessary for the polar switching behaviors. This study offers some valuable information to achieve the polar switching properties by blending bent-core host-guest supramolecular systems with a combination of low molecular weight molecules (as H-acceptors) and polymers (homopolymers/copolymers as $\mathrm{H}$-donors), which could be utilized for supramolecular mixtures in the future.

Acknowledgment. We thank the financial support from the National Science Council of Taiwan (ROC) through NSC 962113-M-009-015. We are also grateful to the National Center for High-performance Computing for computer time and facilities. The powder XRD measurements were supplied by beamline BL17A (charged by Dr. Jey-Jau Lee) of the National Synchrotron Radiation Research Center (NSRRC) in Taiwan.

Supporting Information Available: Chemical structures (covalent-bonded compound $\mathbf{S 1 2}$ and H-bonded complex H12), XRD patterns of polymers A1B0, A16B1, A10B1, A4B1, A1B2, A1B13, A1B5, and A0B1 as well as and polymer complexes A1B0-N, A16B1-N, A10B1-N, A4B1-N, A1B2-N, A1B13-N, and A1B5-N (at various temperatures). This material is available free of charge via the Internet at http:// pubs.acs.org.

\section{References and Notes}

(1) Nakata, M.; Shao, R. F.; Maclennan, J. E.; Weissflog, W.; Clark, N. A. Phvs. Rev. Lett. 2006, 96, 067802.

(2) Rickard, M.; Nakata, M.; Takezoe, H.; Watanabe, J.; Clark, N. A. Phys. Rev. Lett. 2005, 87, 261115.

(3) Meyer, R. B.; Liebert, L.; Strzelecki, L.; Keller, P. J. Phvs., Lett. $1975,36,69$
(4) Chandani, A. D. L.; Ouchi, Y.; Takezoe, H.; Fukuda, A.; Terashima, K.; Furukawa, K.; Kishi, A. Jpn. J. Appl. Phvs. 1989, 28,1261

(5) Fukuda, A.; Takanishi, Y.; Isokaki, T.; Ishikawa, K.; Takezoe, H. J. Mater. Chem. 1994, 4, 997.

(6) (a) Niori, T.; Sekine, F.; Watanabe, J.; Furukawa, T.; Takezoe, H. J. Mater. Chem. 1996, 6, 1231. (b) Sekine, T.; Niori, T.; Watanabe, J.; Furukawa, T.; Choi, S. W.; Takezoe, H. J. Mater. Chem. 1997, 7, 1307.

(7) Yang, P. J.; Lin, H. C. Liq. Crvst. 2006, 33, 587.

(8) Dantlgraber, G.; Diele, S.; Tschierske, C. Chem. Commun. 2002, 2768.

(9) Kosata, B.; Tamba, G. M.; Baumeister, U.; Pelz, K.; Diele, S.; Pelzl, G.; Galli, G.; Samaritani, S.; Agina, E. V.; Boiko, N. I.; Shibaev, V. P.; Weissflog, W. Chem. Mater. 2006, 18, 691.

(10) Sepelj, M.; Lesac, A.; Baumeister, U.; Diele, S.; Bruce, D. W.; Hamersak, Z. Chem. Mater. 2006, 18, 2050.

(11) Keith, C.; Reddy, R. A.; Baumeister, U.; Hahn, H.; Lang, H.; Tschierske, C. J. Mater. Chem. 2006, 16, 3444

(12) Umadevi, S.; Sadashiva, B. K.; Murthy, H. N. S.; Raghunathan, V. A. Soft Matter 2006, 2, 210.

(13) Tamba, M.; Kosata, G.; B.; Pelz, K.; Diele, S.; Pelzl, G.; Vakhovskaya, Z.; Kresse, H.; Weissflog, W. Soft Matter 2006, 2, 60.

(14) Keith, C.; Reddy, R. A.; Tschierske, C. Chem. Commun. 2005, 871.

(15) Barbera, J.; Gimeno, N.; Monreal, L.; Pinol, R.; Ros, M. B.; Serrano, J. L. J. Am. Chem. Soc. 2004, 126, 7190.

(16) Choi, E. J.; Ahn, J. C.; Chien, L. C.; Lee, C. K.; Zin, W. C.; Kim, D. C.; Shin, S. T. Macromolecules 2004, 37, 71.

(17) Chen, X.; Tenneti, K. K.; Li, C. Y.; Bai, Y.; Wan, X.; Fan, X.; Zhou, Q. F.; Rong, L.; Hsiao, B. S. Macromolecules 2007, 40, 840.

(18) Chen, X.; Tenneti, K. K.; Li, C. Y.; Bai, Y.; Zhou, R.; Wan, X.; Fan, X.; Zhou, Q. F. Macromolecules 2006, 39, 517.

(19) Kardas, D.; Prehm, M.; Baumeister, U.; Pociecha, D.; Reddy, R. A.; Mehld, G. H.; Tschierske, C. J. Mater. Chem. 2005, 15, 1722.

(20) Dantlgraber, G.; Baumeister, U.; Diele, S.; Kresse, H.; Luhmann, B.; Lang, H.; Tschierske, C. J. Am. Chem. Soc. 2002, 124, 14852.

(21) Marx, V. M.; Girgis, H.; Heiney, P. A.; Hegmann, T. J. Mater. Chem. 2008, 18, 2983

(22) Ros, M. B.; Serrano, J. L.; Fuente, M. R. de la; Folcia, C. L. J. Mater. Chem. 2005, 15, 5093 .

(23) Reddy, R. A.; Tschierske, C. J. Mater. Chem. 2006, 16, 907.

(24) Martin, P. J.; Bruce, D. W. Liq. Crvst. 2007, 6, 767.

(25) Gimeno, N.; Ros, M. B.; Serrano, J. L.; Fuente, M. R. de la. Angew. Chem. Int. Ed. 2004, 43, 5235.

(26) (a) Barbera, J.; Gimeno, N.; Pintre, I.; Ros, M. B.; Serrano, J. L. Chem. Commun. 2006, 1212. (b) Yang, P. J.; Wang, L. Y.; Tang, C. Y.; Lin, H. C. J. Polym. Sci., Part A: Polym. Chem., in press.

(27) Gimeno, N.; Ros, M. B.; Serrano, J. L. Chem. Mater. 2008, 20, 1262.

(28) Perez, A.; Gimeno, N.; Vera, F.; Ros, M. B.; Serrano, J. L.; Fuente, M. R. De la. Eur. J. Org. Chem. 2008, 826.

(29) Keith, C.; Reddy, R. A.; Hahn, H.; Lang, H.; Tschierske, C. Chem. Commun. 2004, 1898.

(30) Dantlgraber, G.; Eremin, A.; Diele, S.; Hauser, A.; Kresse, H.; Pelzl, G.; Tschierske, C. Angew. Chem. Int. Ed. 2002, 41, 2408.

(31) Reddy, R. A.; Baumeister, U.; Keith, C.; Tschierske, C. J. Mater. Chem. 2007, 17, 62.

(32) (a) Wang, L. Y.; Chiang, I. H.; Yang, P. J.; Lin, H. C. J. Phvs. Chem. B 2009, 113, 14648. (b) Zenyoji, M.; Takanishi, Y.; Ishikawa, K.; Thisayukta, J.; Watanabe, J.; Takezoe, H. J. Mater. Chem. 1999, 9 , 2775 .

(33) Barmatov, E. B.; Bobrovsky, A. Y.; Pebalk, D. A.; Barmatova, M. V.; Shibaev, V. P. J. Polvm. Sci.,Part A. Polvm. Chem. 1999, 37, 3215 .

(34) Cativiela, C.; Serrano, J. L.; Zurbano, M. M. J. Org. Chem. 1995, $60,3074$.

(35) (a) Wu, C. W.; Lin, H. C. Macromolecules 2006, 39, 7985. (b) Liang, T. C.; Lin, H. C. J. Polvm. Sci. Part A: Polvm. Chem. 2009, 47, 2734. (c) Liang, T. C.; Lin, H. C. J. Mater. Chem. 2009, 19, 4753.

(36) Miyasato, K.; Abe, S.; Takazoe, H.; Fukuda, A.; Kuze, E. Jpn. J. Appl. Phvs. 1983, 22, 661. 